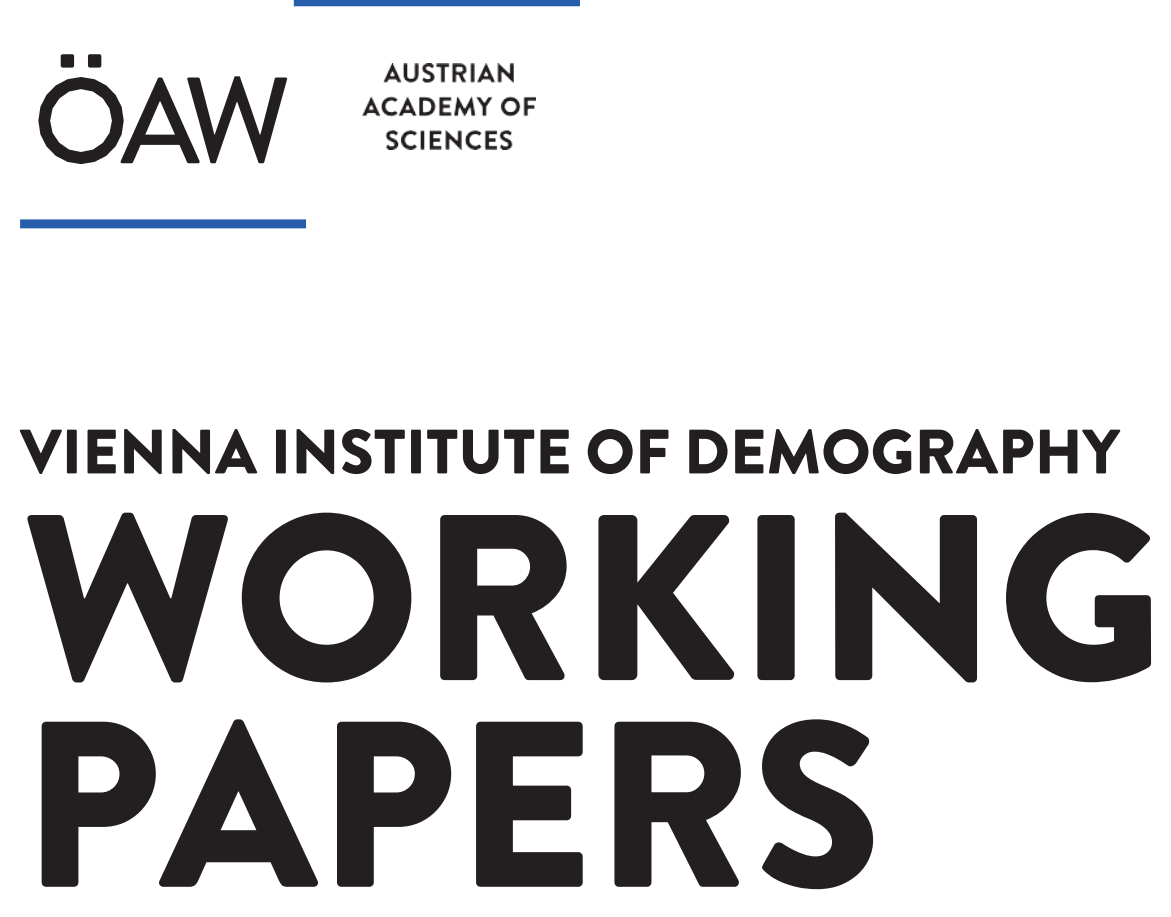

02/2021

\title{
POPULATION GROWTH AND AUTOMATION DENSITY: THEORY AND CROSS-COUNTRY EVIDENCE
}

ANA LUCIA ABELIANSKY \& KLAUS PRETTNER 


\begin{abstract}
We analyse the effects of declining population growth on automation. Theoretical considerations imply that countries with lower population growth introduce automation technologies faster than those with higher population growth. We test the theoretical implication on panel data for 60 countries over the time span 1993-2013. Regression estimates support the theoretical implication, suggesting that a one percent increase in population growth is associated with an approximately two percent reduction in the growth rate of robot density. Our results are robust to the inclusion of standard control variables, different estimation methods, dynamic specifications, and changes with respect measuring robot stocks.
\end{abstract}

\title{
KEYWORDS
}

Automation, Industrial Robots, Demographic Change, Declining Fertility.

\section{AUTHORS}

Ana Lucia Abeliansky, Vienna University of Economics and Business, Department of Economics, Email: ana.lucia.abeliansky@wu.ac.at

Klaus Prettner, Vienna University of Economics and Business, Department of Economics, and Vienna Institute of Demography (OeAW), Wittgenstein Centre for Demography and Global Human Capital (IIASA, OeAW, University of Vienna), Email: klaus.prettner@wu.ac.at

\section{ACKNOWLEDGEMENTS}

We would like to thank Matthias Beulmann, Sebastian Böhm, Isabella Buber-Ennser, Leora Courtney-Wolfman, Emanuel Gasteiger, Oded Galor, Georg Graetz, Volker Grossmann, Volker Meier, Miguel Sánchez-Romero, Holger Strulik, and the participants at the annual meeting of the field committee for population economics of the German Economic Association in Passau 2017, at the annual meeting of the German Economic Association 2017, and at the conference on Dynamics, Economic Growth and International Trade (DEGIT) 2017 for valuable comments and suggestions on an earlier version of this paper that circulated under the title "Automation and Demographic Change." David Höhle provided excellent research assistance. Klaus Prettner gratefully acknowledges the funding provided by the Faculty of Economics and Social Sciences at the University of Hohenheim within its research focus "Inequality and Economic Policy Analysis (INEPA)". 


\section{INTRODUCTION}

Industrialised countries have experienced substantial declines in fertility and in birth rates over the last few decades. For example, the total fertility rate (TFR) for the United States fell from 3.33 children per woman in between 1950 and 1955 to 1.89 children per woman in between 2010 and 2015. During the respective time spans, the crude birth rate (CBR) decreased from 24.4 children per 1000 inhabitants to 12.6 children per 1000 inhabitants (Table 1). These demographic changes have slowed the labour force growth rate in the corresponding countries and will likely lead to a decline in the working-age population in the coming decades. Overall, declining fertility is the central driver of population ageing, contributing much more than increasing life expectancy or changing migration patterns (Weil, 1997; Bloom and Luca, 2016; Prettner and Bloom, 2020).

Many economists have expressed concern about the long-term consequences of these demographic trends (for an overview, see Bloom et al., 2010). For example, progressively shrinking workforces may result in underfunded social security systems and retirement schemes that cannot support an increasing number of retirees (see Gruber and Wise, 1998; Bloom et al., 2007; The Economist, 2011); investment rates might decline when the retiring cohorts deplete their assets (Mankiw and Weil, 1989; Schich, 2008); and the innovative capacity of ageing societies might decrease (e.g., Canton et al., 2002; Borghans and ter Weel, 2002; Gehringer and Prettner, 2019).

Table 1: TFR and CBR in the G7 countries 1950-1955 and 2010-2015

\begin{tabular}{crrrr}
\hline \hline Country & TFR & TFR & CBR & CBR \\
& 1950-1955 & $2010-2015$ & $1950-1955$ & $2010-2015$ \\
\cline { 2 - 5 } Canada & 3.65 & 1.61 & 27.4 & 10.9 \\
France & 2.75 & 2.00 & 19.1 & 12.4 \\
Germany & 2.13 & 1.39 & 15.6 & 8.3 \\
Italy & 2.36 & 1.43 & 18.2 & 8.6 \\
Japan & 3.00 & 1.40 & 23.8 & 8.3 \\
U.K. & 2.18 & 1.92 & 15.1 & 12.6 \\
USA & 3.33 & 1.89 & 24.4 & 12.6 \\
\hline Source: United Nations (2015). & & & &
\end{tabular}

Despite these concerns, behavioural responses to declining fertility might mitigate some of its negative economic effects. For example, if families have fewer children, they will invest more in each child's education, thereby increasing average levels of human capital (Strulik et al., 2013). Similarly, falling fertility levels will translate to parents' increased labour supply because of reductions in time required for childcare (e.g., Bloom et al., 2009; Lee and Mason, 2010; Ashraf et al., 2013).

Regarding the expected labour shortages due to population ageing, there is another silver lining on the horizon: In recent years, robots have started to take over many tasks that were previously regarded as non-automatable. Economists expect that this trend will continue in the future (Frey and Osborne, 2017; Arntz et al., 2017; Acemoglu and Restrepo, 2017b; The Economist, 2019). Prominent examples that have recently received extensive media coverage include autonomous cars and lorries that could soon transport passengers and goods without the need for human drivers; 3D printers that produce customised products, which otherwise require specialised human labour input; and software based on machine learning that has made advances in diagnosing diseases, as well as tools that write newscasts, reports, and even novels on their own. ${ }^{1}$

The effects of automation on employment, wages, and productivity have recently started to catch the attention of economists. From a theoretical perspective, Acemoglu and Restrepo (2018), Chu et al. (2020), Prettner and Strulik (2020), and Hémous and Olsen (2021) propose research and development (R\&D)-based growth models where

\footnotetext{
${ }^{1}$ See, for example, The Economist (2014), Abeliansky et al. (2020), Lanchester (2015), Brynjolfsson and McAfee (2016), and Prettner and Strulik (2020) on different aspects of automation and on new developments.
} 
robots can easily perform the tasks carried out by low-skilled workers and show the pathways through which automation affects long-term economic outcomes. From an empirical perspective, Graetz and Michaels (2018) and Acemoglu and Restrepo (2020) investigate the effects of automation on productivity, wages, and unemployment. Generally speaking, this literature shows that automation has the capacity to increase productivity and thereby economic growth. However, there are also the potential for inequality-enhancing effects. Since robots compete more closely with labour than other types of machines and the income of robots flows to the capital owners that invested in them, automation contributes to the declining labour income share as observed since the 1980s (see Elsby et al., 2013; Karabarbounis and Neiman, 2014; Prettner, 2019). ${ }^{2}$ In addition to its effect on the labour income share, automation can also partly explain decreases in the real wages of low-skilled workers in the United States since the 1970s (Autor and Dorn, 2013; Lankisch et al., 2019). This is because low-skilled workers are (still) easier to substitute with robots than high-skilled workers.

Existing evidence about the employment effects of automation and new technologies is mixed. While Acemoglu and Restrepo (2020) find negative employment effects from the use of industrial robots for the United States, Dauth et al. (2017) focus on Germany and find a small negative effect of industrial robots on employment in manufacturing. This effect is, however, fully compensated by employment gains in the service sector. Gregory et al. (2016) find a positive overall employment effect of automation in Europe, which is in line with automationaugmented search-and-matching labour market models (Guimarães and Mazeda Gil, 2019; Cords and Prettner, 2021).

Our contribution aims to complement work on the labour market impact of automation by looking at the incentives to automate in the first place. We therefore focus on the reverse question of whether countries in which the population growth rate is lower and which are, thus, ageing faster, invest more in automation. While the research mentioned above relates to our paper through its similar emphasis on some causes and consequences of automation, only the independent and parallel works by Acemoglu and Restrepo (2017a) and Acemoglu and Restrepo (2021) investigate the relationship between automation and ageing. Acemoglu and Restrepo (2021) document a positive correlation between the change in the ratio of old workers to young workers between 1990 and 2015 and the change in the number of robots per million hours worked between 1993 and 2014. Additionally, Acemoglu and Restrepo (2021) focus on the age composition of workers and its relationship to automation while also considering the industry dimension and find that a larger share of older workers has a positive effect on automation adoption. We provide a complementary analysis to this work by: i) Showing how a simple general equilibrium growth model that is augmented by automation predicts how demographic changes affect the adoption of robots; ii) empirically testing the theoretical model's implications on panel data about robot adoption and population growth for a broad group of countries. We show that - from a theoretical point of view - countries with lower population growth have greater incentives to invest in automation. Regression estimates support the theoretical prediction, suggesting that a one percent increase in population growth is associated with an approximately 2 percent reduction in the growth rate of the automation density, as measured by the number of robots per thousand inhabitants.

Our paper is structured as follows. In Section 2, we propose a simple general equilibrium framework to highlight the main effect of demographic change on automation. Next, we empirically test the theoretical prediction in Section 3. In Section 4, we discuss our results and draw some policy conclusions.

\section{DECLINING POPULATION GROWTH AND AUTOMATION: THEORETICAL CONSIDERATIONS}

The purpose of this section is to outline a simple general equilibrium model of automation that captures the

\footnotetext{
${ }^{2}$ Apart from automation, demographic change can also partly explain the declining labour income share (d'Albis et al., 2020; Glover and Short, 2020).
} 
basic channel through which demographic change affects automation and to derive the corresponding hypothesis that we test in the empirical part.

\subsection{BASIC ASSUMPTIONS}

Following Prettner (2019) and Antony and Klarl (2020), we consider an economy with three production factors: human labour, traditional capital (e.g., machines, assembly lines), and automation capital (e.g., robots, 3D printers). Time $t$ evolves discretely and the population grows at rate $n$ between time $t$ and time $t+1$. Traditional capital and automation capital can be accumulated and then fully depreciate over the course of one time period (which is one generation or approximately 20 years). In the baseline version of the model, we assume that human labour and traditional physical capital are imperfect substitutes, while automation capital is a perfect substitute for labour. In addition, and consistent with Solow (1956), we assume that households save a constant fraction $s \in(0,1)$ of their total income. We show in extensions that the main theoretical implication does not change when imperfect substitution occurs between robots and workers as in Lankisch et al. (2019), or from an endogenous saving rate as in Gasteiger and Prettner (2020).

\subsection{HOUSEHOLDS AND POPULATION GROWTH}

The population size is given by $N_{t}$ and its evolution is governed by the difference equation

$$
N_{t+1}=(1+n) N_{t},
$$

where $n$ is the population growth rate. Because of the demographic changes outlined in the introduction, this rate is eventually expected to fall to negative values in some countries. As is standard, the labour force at time $t$ is given by $L_{t} \equiv N_{t}$. Consequently, a reduction in the population growth rate translates into a reduction in the growth rate of the workforce, which is realistic in the long run.

Aggregate savings are given by $S_{t+1}=s N_{t}$, where $s$ is the saving rate. There are two saving vehicles: traditional physical capital and automation capital. A no-arbitrage condition holds, ensuring that rational investors would like to hold both types of capital in equilibrium. This condition states that the rates of return on traditional physical capital and on automation capital must be equal.

\subsection{PRODUCTION AND AUTOMATION}

As in Prettner (2019), the production function has a Cobb-Douglas structure with respect to human labour and traditional physical capital. However, the additional non-standard production factor "automation capital" is a perfect substitute for labour such that aggregate output is given by

$$
Y_{t}=K_{t}^{\alpha}\left(L_{t}+P_{t}\right)^{1-\alpha},
$$

where $K_{t}$ refers to traditional physical capital, $P_{t}$ denotes automation capital, and $\alpha \in(0,1)$ is the elasticity of output with respect to traditional physical capital. We abstract from factor-augmenting technological progress that would only act as an additional source of economic growth, but would not alter the central mechanisms in our framework. Perfect competition on factor markets implies that the production factors are paid according to their marginal value product. Normalising the price of final output to 1 , the wage rate and the rates of return on the two 
types of capital are given by

$$
\begin{aligned}
w_{t} & =(1-\alpha)\left(\frac{K_{t}}{L_{t}+P_{t}}\right)^{\alpha}, \\
R_{t+1}^{\text {autom }}=w_{t} & =(1-\alpha)\left(\frac{K_{t}}{L_{t}+P_{t}}\right)^{\alpha}, \\
R_{t+1}^{\text {trad }} & =\alpha\left(\frac{L_{t}+P_{t}}{K_{t}}\right)^{1-\alpha},
\end{aligned}
$$

where $R_{t+1}^{\text {autom }}$ is the gross interest rate paid on automation capital, which is equal to the wage rate, and $R_{t+1}^{\text {trad }}$ is the gross interest rate paid on traditional physical capital. While the ceteris paribus effects of $K_{t}$ and $L_{t}$ on factor remuneration are straightforward, we have non-standard ceteris paribus effects of the accumulation of automation capital: As $P_{t}$ increases, the wage rate decreases because workers compete with automation capital, whereas the rate of return on traditional physical capital increases because automation capital substitutes for workers and therefore raises the marginal product of traditional physical capital. Here, it is important to note that while automation reduces the marginal product of labour and thereby the wage rate, labour productivity as measured by output per worker increases with automation.

The no-arbitrage condition states that investments in both types of capital yield the same rate of return, i.e., $R_{t+1}^{\text {autom }}=R_{t+1}^{\text {trad }} \equiv R_{t+1}$ holds in equilibrium. Setting Equations (2) and (3) equal to each other and solving for $P_{t}$ and $K_{t}$ yields

$$
P_{t}=\frac{1-\alpha}{\alpha} K_{t}-L_{t} \quad \Leftrightarrow \quad K_{t}=\frac{\alpha}{1-\alpha}\left(P_{t}+L_{t}\right)
$$

It would be tempting to conclude from the ceteris paribus effects above that the accumulation of automation capital raises the interest rate. Such a claim, however, would be based on an isolated interpretation of equation (3) without taking the compensating negative effect of automation on the interest rate, which is obvious from equation (2), into account. Due to the no-arbitrage relationship, the net effect of automation on the interest rate is zero in equilibrium and, thus, negligible from an empirical point of view. As a consequence, the argument that we observe low interest rates together with automation cannot be used to refute the validity of the theoretical arguments sketched out above.

Plugging the expression for traditional physical capital from equation (4) into the aggregate production function provides

$$
Y_{t}=\left(\frac{\alpha}{1-\alpha}\right)^{\alpha}\left(L_{t}+P_{t}\right)
$$

Here, it is immediately clear that the standard convergence process to a stationary equilibrium with no longrun growth that we know from the Solow (1956) model without technological progress does not hold anymore. Instead, the production function has the potential to lead to long-run growth if the saving rate is high enough so as to sustain a positive accumulation rate of automation capital (Steigum, 2011; Prettner, 2019; Lankisch et al., 2019). Note that equation (5) resembles the properties of an $A K$ type of production structure. However, in contrast to standard $A K$ type of growth models, this is not due to an assumption that removes the diminishing marginal product of physical capital but due to the structure of the production process in the presence of automation capital.

\subsection{THE EFFECT OF DEMOGRAPHIC CHANGE ON AUTOMATION DENSITY}

Since households save a constant fraction $s \in(0,1)$ of their total income $Y_{t}$ and the economy is closed, aggregate investment is $I_{t}=s Y_{t}$ such that

$$
K_{t+1}+P_{t+1}=s Y_{t}
$$


Substituting for $K_{t+1}$ by the no-arbitrage relationship (4), for $Y_{t}$ by equation (5), and dividing by the population size $N_{t+1}$ provides the following expression

$$
\frac{\alpha\left(p_{t+1}+1\right)}{1-\alpha}+p_{t+1}=s\left(\frac{\alpha}{1-\alpha}\right)^{\alpha} \frac{1+p_{t}}{1+n}
$$

where $p_{t}$ is automation density, i.e., the number of robots relative to the population. Solving this equation for automation density in period $t+1$ as a function of automation density in period $t$ and the parameter values of the model yields the dynamic evolution of automation density

$$
p_{t+1}=s(1-\alpha)\left(\frac{\alpha}{1-\alpha}\right)^{\alpha} \frac{1+p_{t}}{1+n}-\alpha .
$$

According to this equation, it is apparent that a country with a lower population growth rate will have a higher automation density. It is important to note that: i) This result is not a partial equilibrium result, but a general equilibrium result, in the sense that both investors and firms behave optimally; ii) that the effect of population growth is stronger than if it were solely due to the capital delusion mechanism. We summarize the theoretical insight that we aim to test empirically in the second part of the paper in the following proposition.

Proposition 1. Consider a country where the production structure is described by an aggregate production function in the form of equation (5). Households save a constant fraction $s \in(0,1)$ of their total income (labour income plus capital income in the form of traditional physical capital and automation capital), and the no-arbitrage condition (4) holds for both types of investments. Ceteris paribus, a country will experience faster growth in automation density between periods $t$ and $t+1$ if it exhibits a lower population growth rate ( $n$ ).

Proof. Taking the derivative of equation (6) with respect to $n$ yields

$$
\frac{\partial p_{t+1}}{\partial n}=-s(1-\alpha)\left(\frac{\alpha}{1-\alpha}\right)^{\alpha} \frac{1+p_{t}}{(1+n)^{2}}<0
$$

This implies that, given $p_{t}$, the automation density of the next period and, therefore, its growth rate will be lower if $n$ is higher. Note that the derivative is, in general, not equal to -1 , meaning our result is not only due to the fact that automation density is defined as the aggregate stock of automation capital divided by the population size.

The intuition for this finding is the following: A country with a growing population - and workforce - exhibits a comparatively high rate of return on traditional physical capital and a low wage rate, leaving no incentive to invest in automation capital. In fact, the rate of return on investment in automation capital tends to be rather low in such countries. Examples include African countries experiencing rapid population growth such as Mali and Niger, where it would not be an attractive business strategy to invest in automation because of their abundance of labour and correspondingly low wages. By contrast, a country with a stagnating or decreasing population and labour force would see a comparatively high rate of return on investment in automation capital, while the rate of return on investment for traditional physical capital would be relatively low. Examples include ageing European countries like Germany and Italy and ageing East Asian countries like Japan and South Korea where labour is scarce, wages are high, and the interest rate is low.

\subsection{ROBUSTNESS OF THE THEORETICAL RESULTS}

\subsubsection{HOUSEHOLD SAVING DECISIONS}

To show the robustness of our results with respect to relaxing the assumption of an exogenously given saving rate, we now introduce a standard endogenous consumption-savings choice. In doing so, we follow Gasteiger and Prettner (2020) and assume that households live for two time periods: adulthood and retirement. Households 
derive utility from consumption in both time periods, but only earn labour income in the first (Diamond, 1965). Denoting consumption in the first period by $c_{1, t}$, consumption in the second period by $c_{2, t+1}$, and the discount factor by $\beta=1 /(1+\rho)$, with $\rho$ being the discount rate, household lifetime utility $\left(U_{t}\right)$ is given by

$$
U_{t}=\log \left(c_{1, t}\right)+\beta \log \left(c_{2, t+1}\right)
$$

As is standard, the logarithmic utility function ensures analytical tractability. The central result would not change, however, in case of a more general specification in which the elasticity of intertemporal substitution was different from one but households were still risk averse (see the calculations and numerical results in the extensions of Gasteiger and Prettner, 2020). The budget constraint is given by

$$
c_{1, t}+\frac{c_{2, t+1}}{R_{t+1}}=w_{t}
$$

such that discounted lifetime consumption expenditures are equal to lifetime income (consisting only of income in period $t$, because the household is retired in period $t+1$ ). As is well-known in this setting, the optimal consumption-savings choice amounts to consuming a constant fraction of income in the first period and saving the rest for consumption in retirement. With $\tilde{s}_{t}$ denoting savings, optimal choices are given by

$$
c_{1, t}=\frac{1}{1+\beta} w_{t}, \quad \tilde{s}_{t}=\frac{\beta}{1+\beta} w_{t}
$$

The law of motion for the aggregate stock of assets in the overlapping generations model with automation capital is given by

$$
K_{t+1}+P_{t+1}=\tilde{s}_{t} L_{t}
$$

as in Gasteiger and Prettner (2020). Plugging in savings $\left(\tilde{s}_{t}\right)$, wages $\left(w_{t}\right)$, and the traditional physical capital stock as a function of automation capital as given in (4), yields

$$
\frac{\alpha}{1-\alpha}\left(P_{t+1}+L_{t+1}\right)+P_{t+1}=\frac{\beta(1-\alpha)}{1+\beta}\left(\frac{\alpha}{1-\alpha}\right)^{\alpha} L_{t}
$$

Dividing by the size of the adult cohort $L_{t+1}=(1+n) L_{t}$ and rearranging, we arrive at

$$
p_{t+1}=\frac{\beta}{1+\beta}\left(\frac{\alpha}{1-\alpha}\right)^{\alpha} \frac{1}{1+n}-\alpha .
$$

Upon inspection, it is immediately clear that an increase in the population growth rate $(n)$ reduces automation density $\left(p_{t+1}\right)$. Thus, our central result from the case of an exogenous saving choice carries over to a standard setting where the saving rate is endogenously chosen by households. ${ }^{3}$

To show that this result is not a mere capital dilution effect, we now use equation (11) to derive the expression for the traditional physical capital stock (the other saving vehicle) depending on population growth. Hence, we plug in savings $\left(\tilde{s}_{t}\right)$, wages $\left(w_{t}\right)$, and the automation capital stock as a function of traditional physical capital, as given in (4). This yields

$$
k_{t+1}=\alpha+\alpha\left(\frac{\beta}{1+\beta}\right)\left(\frac{1-\alpha}{1+n}\right)\left(\frac{\alpha}{1-\alpha}\right)^{\alpha} .
$$

Next, we take the derivatives of $p_{t+1}$ [Equation (13)] and $k_{t+1}$ [Equation (14)] with respect to $n$, which are, respectively,

$$
\frac{\partial p_{t+1}}{\partial n}=-\frac{[\alpha /(1-\alpha)]^{\alpha} \beta}{(\beta+1)(n+1)^{2}}, \quad \frac{\partial k_{t+1}}{\partial n}=-\frac{(1-\alpha) \alpha[\alpha /(1-\alpha)]^{\alpha} \beta}{(\beta+1)(n+1)^{2}} .
$$

\footnotetext{
(2020).

${ }^{3}$ For the implications of an overlapping generations structure on economic growth in the context of automation, see Gasteiger and Prettner ${ }^{3}$ For the
} 
As expected, both expressions are negative. In addition, automation capital per capita declines by more than traditional physical capital per capita. To observe this effect, we use (15) to derive the following relationship

$$
\frac{\partial k_{t+1}}{\partial n}=(1-\alpha) \alpha \cdot \frac{\partial p_{t+1}}{\partial n}
$$

Since $(1-\alpha) \alpha<1$, the traditional physical capital stock is less affected by a marginal increase in $n$ than the automation capital stock. Thus, our results regarding the effects of population growth on automation adoption cannot solely be explained by a capital dilution effect. These insights are summarised in the following proposition:

\section{Proposition 2.}

- The negative effect of population growth on the adoption of automation capital is robust to a standard extension in which households choose their saving rate endogenously.

- The negative effect of population growth on automation density cannot be explained as solely originating in a capital dilution effect.

Proof. The proof follows directly from the derivations and explanations above.

\subsubsection{SKILL-SPECIFIC HETEROGENEITIES OF WORKERS}

Next, we demonstrate that our results are robust to introducing different skill levels of workers in the production function. To this end, we assume that the representative firm can now employ both low-skilled workers $\left(L_{u, t}\right)$ and high-skilled workers $\left(L_{s, t}\right)$ in addition to the two types of capital according to the constant elasticity of substitution (CES) production function

$$
Y_{t}=\left[L_{s, t}^{\gamma}+\left(P_{t}+L_{u, t}\right)^{\gamma}\right]^{\frac{1-\alpha}{\gamma}} K_{t}^{\alpha},
$$

where $\gamma \in(-\infty, 1]$ determines the elasticity of substitution between low-skilled workers and high-skilled workers as $\sigma=1 /(1-\gamma)$. Note that workers with different skills are perfect substitutes for $\gamma=1$ and perfect complements for $\gamma \rightarrow-\infty$. The empirically relevant range for this parameter is $\gamma \in(0,0.5)$ such that low-skilled and high-skilled workers are gross substitutes and $\sigma$ lies in the range $\sigma \in(1,2)$ (Autor, 2002; Acemoglu, 2009). Generally, robots are only perfect substitutes for low-skilled workers, while they are imperfect substitutes for high-skilled workers. Now, the workforce size is given by $L_{t}=L_{u, t}+L_{s, t}$ and the shares of high-skilled and low-skilled workers are $l_{s, t}=L_{s, t} /\left(L_{s, t}+L_{u, t}\right)$ and $l_{u, t}=L_{u, t} /\left(L_{s, t}+L_{u, t}\right)$. Output per worker then follows in a straightforward manner as

$$
y_{t}=\left[l_{s, t}^{\gamma}+\left(p_{t}+l_{u, t}\right)^{\gamma}\right]^{\frac{1-\alpha}{\gamma}} k_{t}^{\alpha} .
$$

Based on the modified production function (17) and the assumption of perfect competition in the factor markets, it follows that

$$
\begin{aligned}
R_{t+1}^{\text {trad }} & =\alpha K_{t}^{\alpha-1}\left[L_{s, t}^{\gamma}+\left(L_{u, t}+P_{t}\right)^{\gamma}\right]^{\frac{1-\alpha}{\gamma}}, \\
R_{t+1}^{\text {autom }} & =(1-\alpha) K_{t}^{\alpha}\left(L_{u, t}+P_{t}\right)^{\gamma-1}\left[L_{s, t}^{\gamma}+\left(L_{u, t}+P_{t}\right)^{\gamma}\right]^{\frac{1-\alpha-\gamma}{\gamma}} .
\end{aligned}
$$

Again, for rational investors, a no-arbitrage condition $R_{t+1}^{\text {autom }}=R_{t+1}^{\text {trad }} \equiv R_{t+1}$ holds that enables deriving the equilibrium stock of traditional physical capital depending on automation capital and the employment of both types of workers as

$$
K_{t}=\frac{\alpha\left(L_{u, t}+P_{t}\right)^{1-\gamma}\left[\left(L_{u, t}+P_{t}\right)^{\gamma}+L_{s, t}^{\gamma}\right]}{1-\alpha} .
$$


Dividing equation (21) by the number of workers yields the traditional physical capital stock per worker $\left(k_{t}=\right.$ $\left.K_{t} / L_{t}\right)$ as a function of automation capital per worker $\left(p_{t}=P_{t} / L_{t}\right)$ and the shares of skilled and unskilled workers, $l_{s, t}$ and $l_{u, t}$ :

$$
k_{t}=\frac{\alpha\left(l_{u, t}+p_{t}\right)+\alpha l_{s, t}^{\gamma}\left(l_{u, t}+p_{t}\right)^{1-\gamma}}{1-\alpha}
$$

Aggregate investment is again given by $I_{t}=s Y_{t}$ and - under full depreciation over the course of one generation - the accumulation equation for both types of capital follows as

$$
P_{t+1}+K_{t+1}=s Y_{t}
$$

Dividing by $L_{t+1}=(1+n) L_{t}$ and plugging (18) and the optimal factor input relationship (22) from above into this result yields

$$
\begin{aligned}
& p_{t+1}+\frac{\alpha\left(l_{u, t+1}+p_{t+1}\right)+\alpha l_{s, t+1}^{\gamma}\left(l_{u, t+1}+p_{t+1}\right)^{1-\gamma}}{1-\alpha} \\
& =\frac{s}{1+n}\left[l_{s, t}^{\gamma}+\left(p_{t}+l_{u, t}\right)^{\gamma}\right]^{\frac{1-\alpha}{\gamma}}\left[\frac{\alpha\left(l_{u, t}+p_{t}\right)+\alpha l_{s, t}^{\gamma}\left(l_{u, t}+p_{t}\right)^{1-\gamma}}{1-\alpha}\right]^{\alpha} .
\end{aligned}
$$

Due to its complexity, this equation cannot be solved analytically, so we instead employ a numerical illustration of the effects of population growth on the adoption of automation capital using the parameter values in Table 2 and an initial stock of automation capital of $p_{t}=1$. Note that the population growth rate refers to a yearly value and is converted into generational terms under the assumption that one period in our setting lasts for 20 years.

Table 2: Parameter values for the numerical illustration

\begin{tabular}{lrr}
\hline \hline Parameter & Value & Source \\
\hline$s$ & $21 \%$ & Grossmann et al. (2013) \\
$n$ & $0.9 \%$ & World Bank (2016) \\
$\alpha$ & $1 / 3$ & Acemoglu (2009); Grossmann et al. (2013) \\
$l_{s}$ & $23 \%$ & Lankisch et al. (2019) \\
$\gamma$ & 0.15 & Plausible estimate according to Autor (2002) and \\
& & Acemoglu (2009) that still allows for growth in robots \\
\hline \hline
\end{tabular}

Our results show that an increase in the population growth rate from 0.9 percent per year to one percent per year decreases the stock of automation capital in period $t+1$ from 1.496 to 1.464 . Consequently, our central result from the model's baseline version is robust to the introduction of different skill types of which only low-skilled workers can be perfectly substituted by robots.

Two comments about the model's empirical implementation should be raised at this stage: First, the closed economy assumption might not be fulfilled in reality. However, the empirical results do not depend on whether or not the model refers to a closed economy. This is because population growth - which is used as a proxy for $n$ - also includes migration, while the gross investment rate - which is used as a proxy for the saving rate $s$ includes international capital flows. Second, because the regressions control for the gross saving rate, the potential endogeneity of the saving rate $s$ to demographic change is unproblematic. 


\section{DECLINING POPULATION GROWTH AND AUTOMATION: EMPIRICAL RESULTS}

This section first introduces the data, then empirically tests Proposition 1, and provides a number of robustness checks. Table 3 provides a first glimpse of whether the proposition's implied result is consistent with the data. The table depicts the number of industrial robots per 10,000 employees as of 2015 alongside the average population growth rate from the preceding five-year interval (2010 to 2015) for the nine countries with the highest robot usage. Compared to elsewhere, the population growth rate for these countries appears relatively low and sometimes negative. However, this could be because these countries are richer, implying that they have a lower fertility rate and are simultaneously able to invest more in automation. Therefore, the next section tests whether this theoretical implication is borne by the data via a thorough econometric analysis.

Table 3: Robots per 10,000 employees in manufacturing and population growth in the top 9 countries in terms of robot usage

\begin{tabular}{lrr}
\hline \hline Country & $\begin{array}{r}\text { Robots per 10,000 employees } \\
\text { in manufacturing }\end{array}$ & $\begin{array}{r}\text { Average population growth } \\
\text { between 2010 and 2015 }\end{array}$ \\
\hline South Korea & 347 & $0.48 \%$ \\
Japan & 339 & $-0.12 \%$ \\
Germany & 261 & $0.16 \%$ \\
Italy & 159 & $0.07 \%$ \\
Sweden & 157 & $0.83 \%$ \\
Denmark & 145 & $0.42 \%$ \\
United States & 135 & $0.75 \%$ \\
Spain & 131 & $-0.21 \%$ \\
Finland & 130 & $0.50 \%$ \\
\hline \hline
\end{tabular}

Note: The population growth rate is calculated as the average population growth rate from 2010 to 2015 Sources: International Federation of Robotics (2015); United Nations (2015).

\subsection{DATA DESCRIPTION}

The only currently available dataset for studying robot adoption is compiled by the International Federation of Robotics (IFR). The IFR reports the yearly delivery of "multipurpose manipulating industrial robots" for several countries, as defined by the International Organization for Standardization, starting from 1993. Our data covers 1993 through 2013 because the data for 2014 are unreliable: there are several zeroes that seem to be reporting errors compared to previous values in the data series. Our baseline specification uses three-year averages from the data, which provide seven time periods for estimation. The sample includes 60 countries for which the data are available (Table A.1 displays summary statistics and Table A.2 contains the list of countries, both in the Appendix). Since the three NAFTA countries (Canada, the United States, and Mexico) report their values jointly until 2011, they were combined into one geographical unit. ${ }^{4}$

The IFR also reports the robot deliveries and robot stock at the industry level, and assumes that robots have a lifetime horizon of 12 years, after which they are deployed (International Federation of Robotics, 2016). Following Graetz and Michaels (2018), we use an alternative approach to calculate robot stock (for all robots and separately for robots in the manufacturing industry) that relies on the perpetual inventory method under the assumption of a 10 percent depreciation rate. Robustness checks also use alternative depreciation rates of 5 percent and 15 percent. Like Graetz and Michaels (2018), we prefer this method to that used by the IFR, because it is more in line with the standard economics literature. 1993 is our first value for the constructed series, since it is when the IFR started reporting robot stocks. Although all included countries report the total robot stock, not all report the yearly stock or deliveries at the industry level. Given our primary interest in robots used by the manufacturing sector, we follow

\footnotetext{
${ }^{4}$ The total sample size contains 300 observations that we can use for the empirical analysis (60 countries over five time periods). Since we are using a lag of one period and computing the $(\log )$ growth rate, we lose two periods of observations.
} 
Graetz and Michaels (2018) and take the average share of manufacturing robot deliveries over the total deliveries of robots (when the data were available), construct an average share, and impute the values for manufacturing robot deliveries, as well as for the initial stock of robots (when the corresponding data were not available). Table A.3 (see Appendix) shows the first reported year of robot data, and is disaggregated at the industry level for countries that had gaps in the reported data.

The following figures show how robot density has evolved between the first period from the sample (19931995) and the last period (2011-2013). Figure 1 differentiates between percentiles (covering 1993 to 1995), reporting the 75th percentile in the lightest shade of blue, and proceeding to get darker at the 90th percentile, 95th percentile, and finally the remaining 5 percent of the distribution (the 75th percentile was used as the first cutoff since many countries have zeroes in this period). By comparison, Figure 2 shows the same data for 2011 to 2013, using the same thresholds as in the previous figure and demonstrates a strong increase in robot density, especially in Europe and East Asia. Similar figures for robots only used in the manufacturing sector are displayed in the Appendix (Figures A.1 and A.2).

Figure 1: Average robot density for 1993-1995

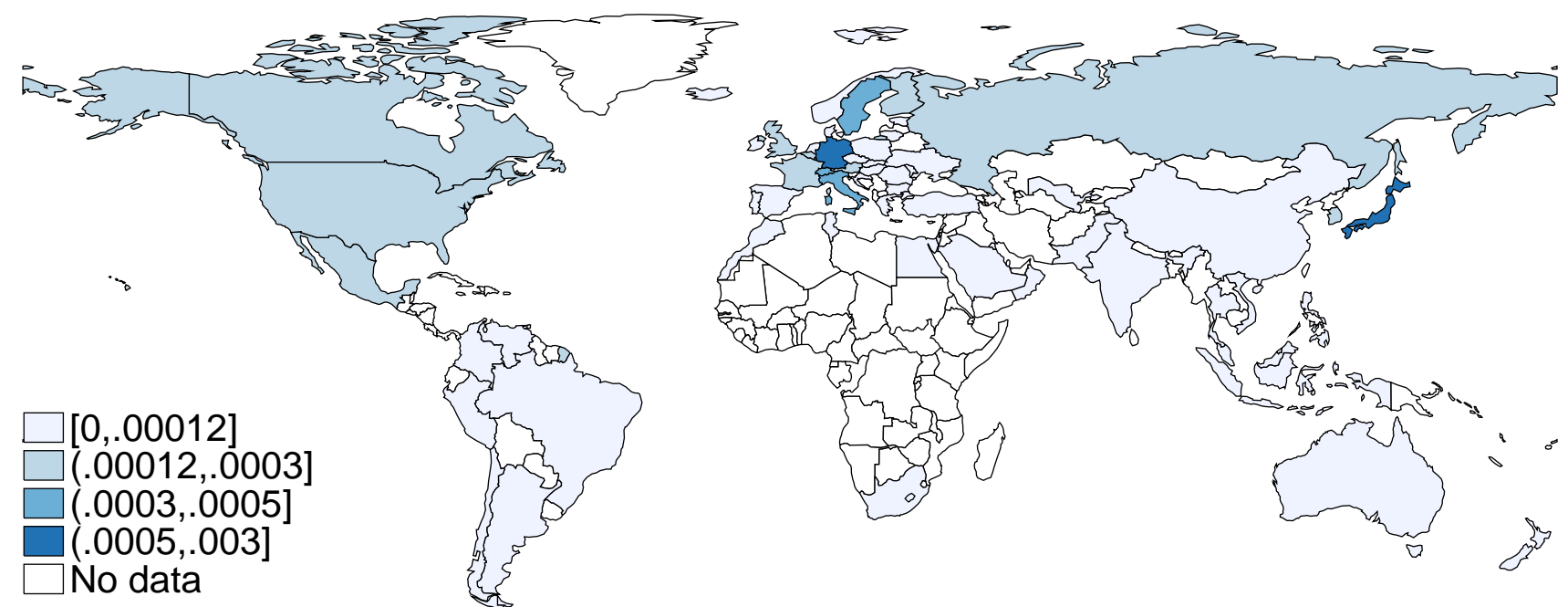

Source: International Federation of Robotics (2015) and World Development Indicators. Note: The USA, Canada and Mexico have the same values because of joint reporting.

Figure 2: Average robot density for 2011-2013

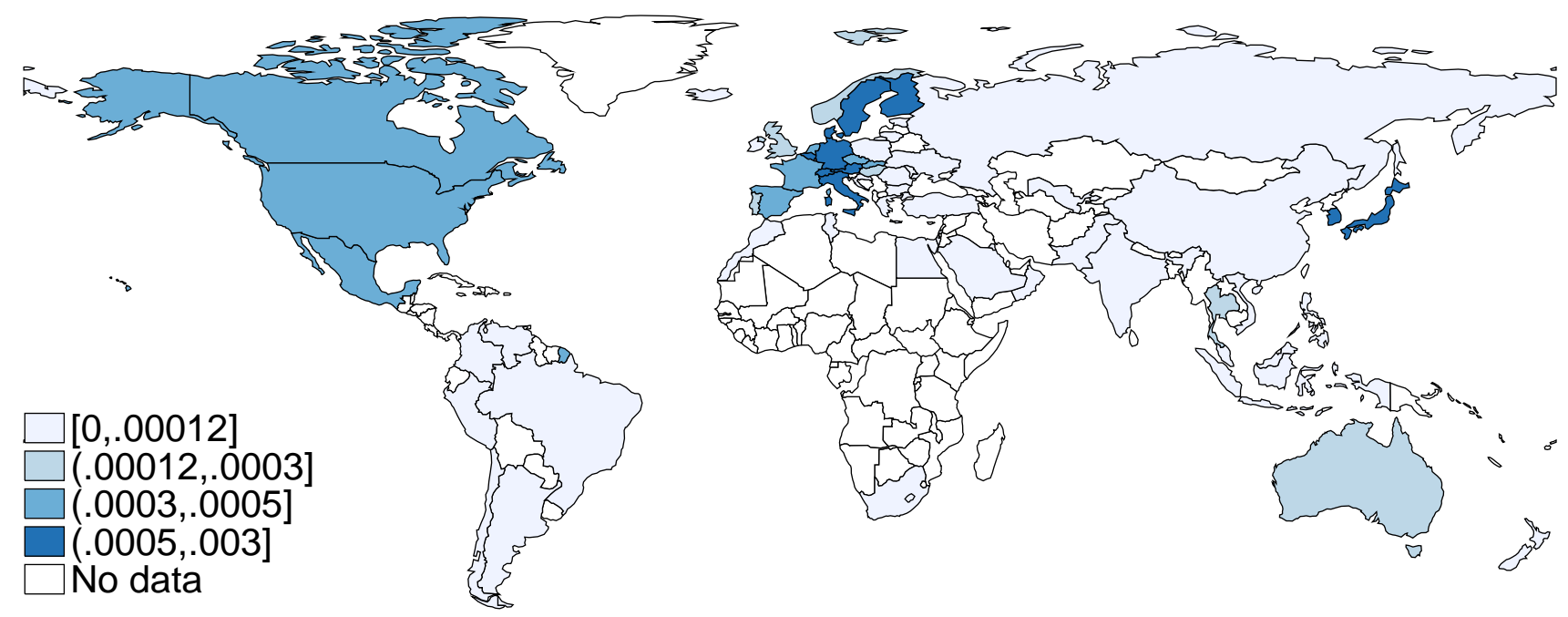

Source and Note: See Figure 1.

We also collected information from the International Monetary Fund (IMF) on the investment share (over GDP). 
We constructed our investment variable summing the reported values of private investment, public investment, and joint ventures between the state and the private sector. For additional control variables, we also included GDP per capita (measured in constant \$ US with a base year of 2010 from the World Development Indicators), openness (measured as exports and imports over GDP), the gross enrolment ratio in secondary schools (as in Busse and Spielmann $(2006)^{5}$ ) and the service sector contribution to total GDP. Finally, we retrieved life expectancy and the dependency ratio from the World Development Indicators, and industrial robot exports from UN Comtrade, standardised by GDP. Table A.4 (in the Appendix) describes the variables' construction.

\subsection{EMPIRICAL SPECIFICATION}

Based on Proposition 1, we estimate the relationship between robots adoption and population growth, using the following equation:

$$
\ln \left(\hat{p}_{i, t}\right)=c+\alpha \ln \left(n_{i, t-1}\right)+\beta \ln \left(s_{i, t-1}\right)+\gamma \ln \left(x_{i, t-1}\right)+d_{t}+\epsilon_{i, t}
$$

where $\hat{p}_{i, t}$ is the growth rate of robot density (either manufacturing robots or the total amount of robots per 1000 inhabitants), $n_{i, t-1}$ is the population growth rate between periods $t-1$ and $t-2, s_{i, t-1}$ is the gross investment rate in period $t-1, x_{i, t-1}$ is a vector of further control variables that will be used in the robustness analysis (e.g., GDP per capita, openness, etc), and $d_{t}$ are time-specific effects to control for events and trends that affect all countries in the same manner, e.g., the global economic and financial crisis that started in 2007. To address the zeroes and negative values in the dependent variable and population growth rate, we employed the zero-skewness log transformation (Box and Cox, 1964). ${ }^{6}$, which alleviates concerns about heteroscedasticity and non-linearities in the non-transformed variables. Likewise, we use three-year averages to reduce problems related to measurement errors and business-cycle effects. While the economic growth literature usually relies on five-year averages, such intervals would only provide us with two consecutive time periods to use in our estimation.

We first estimate equation (24) using pooled OLS (POLS) and then proceed with a random-effects (RE) and a fixed-effects (FE) specification. Finally, we take the potential dynamics into account by including the lagged dependent variable in the regressions and by applying various corrected fixed effects estimators (CorrFE) following Bruno (2005a,b), and the system GMM estimator [GMM (sys)] from Blundell and Bond (1998). Note that both of these types of estimators are seen as remedies for the Nickell (1981) bias in a dynamic panel data setting. We report the results for the total amount of robots and then also separately for the subset of manufacturing robots. Moreover, we assess the robustness of our results by adding proxies for education, GDP per capita, openness, life expectancy, the dependency ratio, and the value of exported robots. In other robustness checks reported in the Appendix (see Tables A.20 - A.33), we consider different depreciation rates in the construction of the robot data series (5 percent and 15 percent instead of 10 percent), a different transformation of robot adoption and population growth rates [a "neglog" transformation as used by Whittaker et al. (2005)], and percentile changes as in Graetz and Michaels (2018).

Based on the theoretical considerations, we expect to find a negative coefficient for the population growth rate that is smaller than -1 and a positive sign for the gross investment rate that is the standard proxy used for the gross saving rate $s$. Again, it is important to note that the population growth rate takes migration into account and that the gross investment rate includes international capital flows. When we include the controls, we expect a positive coefficient for GDP per capita because higher incomes imply a stronger incentive to employ robots. Furthermore, a better-educated population might be more inclined to invest in (or adapt to) robots, such that the coefficient of education should also be positive. However, we have no a priori expectation regarding the sign of the estimated coefficient for openness: On the one hand, as countries become more open, they might need fewer robots because

\footnotetext{
${ }^{5}$ The natural choice for an educational proxy variable would have been mean years of schooling as reported by Barro and Lee (2013). However, this variable is only available in 5-year intervals.

${ }^{6}$ We created a new variable in the following manner: $z=\ln$ (growth rate $-k$ ), choosing $k$ such that the skewness of $z$ is zero. The correlation between the non-transformed variables and the variables in logarithms (naturally omitting the zeroes and the negative values) is 0.89 .
} 
domestic production could more easily be substituted by imports; on the other hand, open economies are also subject to stronger international competition, which could incentivise them to automate production in search of efficiency gains. Regarding the dependency ratio, we would expect that higher dependency is associated with faster robot growth; higher robot exports with lower national sales of industrial robots; and the expectation that the estimated life expectancy coefficient is ambiguous, whereas higher life expectancy would suggest a lower need to replace humans with robots. Given the demand for geriatric healthcare and the potential for robots to supply healthcare Ao Ahe Alderly, Ahe Aoefficient Aould Ae positive.

\subsection{EMPIRICAL ESTIMATES}

\subsubsection{BASELINE ESTIMATES}

Table 4 contains the regression outputs from a baseline specification of equation (24). Drawing on our theoretical considerations, we employ two crucial variables as regressors: the population growth rate and investment rate. We observe a negative relationship between population growth and the robot density growth rate, which is statistically significant in all specifications except for one. Only column (1), which reports the POLS regression, shows that the coefficient is not statistically significant. This is most likely due to a lack of accounting for country-level heterogeneity. Our results are robust to the dynamic specifications using the corrected fixed effects estimators, as well as the system GMM estimator that also controls for regressor endogeneity using internal instruments. Regarding the choice between corrected fixed effects and system GMM, we prefer the corrected fixed effects specifications because Judson and Owen (1999) report that this estimator performs better when the amount of time periods is smaller than 10, as in our sample. Although the estimated coefficient for the lagged dependent variable is statistically significant, its size does not provide strong evidence for using a dynamic specification. We prefer the fixed effects specification for the non-dynamic panel data estimators, as we conducted a Hausman test that indicated that the results from the random effects specification were inconsistent). Thus, we need to control for unobserved heterogeneity. The coefficient estimate for the population growth rate for the fixed-effects specification suggests that when population growth increases by one percent, robot density growth will decrease by two percent. Regarding the main control variable (the investment share), we find the expected positive relationship, although it is not statistically significant.

Since one might not be able to rule out a positive relationship between population growth and savings, we also estimate the indirect effect of population growth on automation via the saving rate. Thus, we ran an auxiliary regression:

$$
\ln s_{i, t-1}=c_{2}+\alpha_{2} \ln n_{i, t-1}+d_{t}+\epsilon_{i, t-1} .
$$

In this new specification, the effect of population growth on automation growth is given by $\alpha$ (from the baseline regression) plus $\beta \cdot \alpha_{2}$. After retrieving the coefficient $\alpha_{2}$ from Table A.5 in the Appendix and $\alpha$ and $\beta$ from Table 4, we can calculate the overall effect of population growth (taking the values from column (3)) as $-2.030+0.387 \cdot 0.419=-1.868$, which is smaller than zero. ${ }^{7}$

Table 5 shows the results for the growth rate of manufacturing robot density (instead of all robots). We again find the negative association between population growth and growth of the robot density, as suggested by Proposition 1, with the coefficient size being similar to those reported in Table 4. As in the previous case, we see an insignificant positive correlation between the investment rate and the growth rate for manufacturing robot density. Here, there is even less evidence for the need of a dynamic specification because the coefficients from the lagged dependent variable are smaller in size and not even statistically significant for the system GMM estimator.

${ }^{7}$ We thank an anonymous referee for suggesting this robustness check. 
Table 4: The relationship between total robot growth and population growth

\begin{tabular}{|c|c|c|c|c|c|c|c|}
\hline & $\begin{array}{c}(1) \\
\text { POLS }\end{array}$ & $\begin{array}{l}\text { (2) } \\
\mathrm{RE}\end{array}$ & $\begin{array}{l}\text { (3) } \\
\mathrm{FE}\end{array}$ & $\begin{array}{c}(4) \\
\text { CorrFE (bb) }\end{array}$ & $\begin{array}{c}(5) \\
\text { CorrFE }(a b)\end{array}$ & $\begin{array}{c}\text { (6) } \\
\text { CorrFE (ah) }\end{array}$ & $\begin{array}{c}\text { (7) } \\
\text { GMM (sys) }\end{array}$ \\
\hline$\hat{p}_{t-1}$ & & & & $\begin{array}{c}0.316^{* * *} \\
(0.779)\end{array}$ & $\begin{array}{c}0.259^{* * *} \\
(0.090)\end{array}$ & $\begin{array}{c}0.245^{* *} \\
(0.0987)\end{array}$ & $\begin{array}{l}0.226^{* *} \\
(0.111)\end{array}$ \\
\hline$n_{t-1}$ & $\begin{array}{l}-0.539 \\
(0.328)\end{array}$ & $\begin{array}{l}-0.694^{*} \\
(0.354)\end{array}$ & $\begin{array}{c}-2.030^{* *} \\
(0.894)\end{array}$ & $\begin{array}{c}-1.690^{* * *} \\
(0.597)\end{array}$ & $\begin{array}{c}-1.803^{* * *} \\
(0.562)\end{array}$ & $\begin{array}{c}-1.828^{* * *} \\
(0.557)\end{array}$ & $\begin{array}{c}-3.515^{* * *} \\
(1.205)\end{array}$ \\
\hline$s_{t-1}$ & $\begin{array}{c}0.063 \\
(0.119)\end{array}$ & $\begin{array}{c}0.090 \\
(0.129)\end{array}$ & $\begin{array}{c}0.419 \\
(0.495)\end{array}$ & $\begin{array}{c}0.304 \\
(0.357)\end{array}$ & $\begin{array}{c}0.324 \\
(0.340)\end{array}$ & $\begin{array}{c}0.335 \\
(0.341)\end{array}$ & $\begin{array}{c}0.115 \\
(0.473)\end{array}$ \\
\hline Country FE & no & no & yes & yes & yes & yes & - \\
\hline Time FE & yes & yes & yes & yes & yes & yes & yes \\
\hline $\mathrm{AR}(2)$ test & - & - & - & - & - & - & 0.922 \\
\hline Hansen test & - & - & - & - & - & - & 0.623 \\
\hline Countries & 60 & 60 & 60 & 60 & 60 & 60 & 60 \\
\hline Observations & 300 & 300 & 300 & 300 & 300 & 300 & 300 \\
\hline
\end{tabular}

Note: $\overline{\overline{\text { Standard errors in parenthesis. } * * * * *} \text {, and }{ }^{*} \text { indicate significance at the } 1,5 \text {, and } 10 \text { percent level, respectively. The standard }}$ errors in columns (1), (2), and (3) are clustered at the country level, while those from (4) to (6) are bootstrapped with 50 iterations. Column (7) uses collapsed instruments and an orthogonal transformation. All of the variables are in logarithms, while population growth and robot growth were transformed with the zero-skewness log transformation. CorrFE refers to the corrected fixed effects with $b b$ indicating initialization by the Blundell and Bond (1998) estimator, $a b$ initialization by the Arellano and Bond (1991) estimator, and $a h$ initialisation by the Anderson and Hsiao (1982) estimator. $\hat{p}_{t-1}$ is the growth rate of robot density (either manufacturing robots or the total amount of robots per 1000 inhabitants) between periods $t-1, t-2, n_{i, t-1}$ is the population growth rate between periods $t-1$, and $t-2$, and $s_{i, t-1}$ is the gross investment rate in period $t-1$.

Table 5: The relationship between manufacturing robot growth and population growth

\begin{tabular}{|c|c|c|c|c|c|c|c|}
\hline & $\begin{array}{c}(1) \\
\text { POLS }\end{array}$ & $\begin{array}{l}(2) \\
\mathrm{RE}\end{array}$ & $\begin{array}{l}\text { (3) } \\
\mathrm{FE}\end{array}$ & $\begin{array}{c}(4) \\
\text { CorrFE (bb) }\end{array}$ & $\begin{array}{c}(5) \\
\text { CorrFE (ab) }\end{array}$ & $\begin{array}{c}\text { (6) } \\
\text { CorrFE (ah) }\end{array}$ & $\begin{array}{c}\text { (7) } \\
\text { GMM (sys) }\end{array}$ \\
\hline$\hat{p}_{t-1}$ & & & & $\begin{array}{c}0.264^{* * *} \\
(0.077)\end{array}$ & $\begin{array}{l}0.197^{* *} \\
(0.086)\end{array}$ & $\begin{array}{c}0.180^{* *} \\
(0.0914)\end{array}$ & $\begin{array}{c}0.120 \\
(0.120)\end{array}$ \\
\hline$n_{t-1}$ & $\begin{array}{l}-0.457 \\
(0.336)\end{array}$ & $\begin{array}{l}-0.632^{*} \\
(0.368)\end{array}$ & $\begin{array}{l}-2.185^{* *} \\
(0.973)\end{array}$ & $\begin{array}{c}-1.950^{* * *} \\
(0.613)\end{array}$ & $\begin{array}{c}-2.055^{* * *} \\
(0.570)\end{array}$ & $\begin{array}{c}-2.078^{* * *} \\
(0.566)\end{array}$ & $\begin{array}{c}-3.908^{* * *} \\
(1.237)\end{array}$ \\
\hline$s_{t-1}$ & $\begin{array}{c}0.026 \\
(0.095)\end{array}$ & $\begin{array}{c}0.043 \\
(0.101)\end{array}$ & $\begin{array}{c}0.175 \\
(0.490)\end{array}$ & $\begin{array}{c}0.132 \\
(0.365)\end{array}$ & $\begin{array}{c}0.146 \\
(0.343)\end{array}$ & $\begin{array}{c}0.155 \\
(0.343)\end{array}$ & $\begin{array}{c}0.311 \\
(0.401)\end{array}$ \\
\hline Country FE & no & no & yes & yes & yes & yes & - \\
\hline Time FE & yes & yes & yes & yes & yes & yes & yes \\
\hline $\mathrm{AR}(2)$ test & - & - & - & - & - & - & 0.623 \\
\hline Hansen test & - & - & - & - & - & - & 0.506 \\
\hline Countries & 60 & 60 & 60 & 60 & 60 & 60 & 60 \\
\hline Observations & 300 & 300 & 300 & 300 & 300 & 300 & 300 \\
\hline
\end{tabular}

Note: $\overline{\overline{S t a n d a r d} \text { errors in parenthesis. }{ }^{* * *},{ }^{* *}, \text { and } * \text { indicate significance at the } 1,5 \text {, and } 10 \text { percent level, respectively. The standard }}$ errors in columns (1), (2), and (3) are clustered at the country level, while those from (4) to (6) are bootstrapped with 50 iterations. Column (7) uses collapsed instruments and an orthogonal transformation. All of the variables are in logarithms, while population growth and robot growth were transformed with the zero-skewness log transformation. CorrFE refers to the corrected fixed effects with $b b$ indicating initialization by the Blundell and Bond (1998) estimator, $a b$ initialization by the Arellano and Bond (1991) estimator, and $a h$ initialisation by the Anderson and Hsiao (1982) estimator. $\hat{p}_{t-1}$ is the growth rate of robot density (either manufacturing robots or the total amount of robots per 1000 inhabitants) between periods $t-1, t-2, n_{i, t-1}$ is the population growth rate between periods $t-1$, and $t-2$, and $s_{i, t-1}$ is the gross investment rate in period $t-1$. 


\subsubsection{ROBUSTNESS ANALYSIS}

We provide several robustness checks in Section A.4 ( see Appendix). The first controls for three potential omitted variables: GDP per capita, openness of the economy, and secondary school enrolment (Tables A.6 and A.7). Again, regression results show a negative correlation between robot density growth and population growth. Further, we report the same specification as before, but omit the controls that were not statistically significant (i.e., secondary school enrolment and openness) in Tables A.8 and A.9. The results do not change dramatically, but when employing the system GMM estimator, the significance of the puzzling negative sign of per capita GDP vanishes. To control for a potential structural change in the economy, we report the results of adding the (log) of the service sector size as a percentage of overall value added, which leaves the results fairly unchanged (refer to Table A.10 for total robots and Table A.11 for manufacturing robots). Next, we use two proxies for investment as alternatives to the saving rate: the capital stock (in 2005 \$ US) and gross fixed capital formation as a fraction of GDP (Tables A.12 and A.14; Tables A.13 and A.15 show the results for the total robots and manufacturing robots, respectively). The tables show that capital stock is not significantly correlated with the pace of robot adoption. Moreover, the population growth estimates remain close in value to our previous estimates and statistically significant for all relevant specifications. The same applies for the regressions, which included a different set of control variables: the dependency ratio, life expectancy, and industrial robot exports (Tables A.16 and A.17).

Furthermore, the results remained unchanged after using two-year averages instead of averaging the data over three years (Tables A.18 and A.19). We also constructed two alternative robot stocks using 5 percent and 15 percent as alternative depreciation rates (results shown in Tables A.20 and A.22 (for the total stock of robots) and Tables A.21 and A.23 (for manufacturing robots)). We find no substantial differences from our previous estimates. Another sensitivity analysis excludes Germany, South Korea, the NAFTA countries, Japan, and China because they have the highest (manufacturing) robot density and also very low fertility rates. However, after excluding these countries, the results remain stable (see Tables A.24 and A.25). Next, we extended the sample include two extra available years (2014 and 2015) and replaced population growth with labour force growth (see Tables A.26 and A.27).

Another concern is that our results depend on the zero-skewness log transformation. Therefore, a further robustness check uses the neglog transformation for both the population growth rate and the robot density growth rate. Results again remain similar to the baseline specification (Tables A.30 and A.31 of the Appendix). Our final robustness check follows Graetz and Michaels (2018) and converts the dependent variable into percentiles (Tables A.32 and A.33). Once more, the qualitative relationships between the variables remain consistent with our baseline regressions. ${ }^{8}$

\section{CONCLUSIONS}

We propose a simple theoretical framework of production for countries that are subject to declining population growth in the age of automation. In so doing, we introduce automation as a new production factor that shares properties of labour in the production process on the one hand, and properties of traditional physical capital in the accumulation process on the other hand. We show that lower population growth implies a stronger incentive to invest in the adoption of automation. Our empirical estimates and several robustness checks support this theoretical prediction, demonstrating that countries with lower population growth have higher incentives to invest in automation: A one percent increase in population growth is associated with an approximately two percent reduction in the growth rate of automation density, as measured by the number of robots per thousand inhabitants.

${ }^{8}$ Section A.4 in the Appendix further elaborates on the robustness analysis. 
In terms of policy implications, our findings suggest that countries that are experiencing substantial demographic challenges will be the first to adopt and/or invent new automation technologies. This, in turn, might help them overcome potential negative effects that declining population growth and population ageing may have on long-run economic prosperity - issues that the media is also heavily concerned with (see, for example, The Washington Post, 2016).

Our framework is deliberately simple. However, there are several features that our stylised model does not capture in reality. For example, i) different (manufacturing) sectors in the economy might use robots with different intensities; ii) innovation and automation are endogenous. Analysing the extent to which the differences in robot use across sectors change with declining population growth is definitely a worthwhile research question in and of itself. In addition, it would be interesting to analyse the effects of changing population growth on the incentives to invest in innovation and automation within frameworks developed by Acemoglu and Restrepo (2018), Chu et al. (2020), Prettner and Strulik (2020), and Hémous and Olsen (2021). Since these are beyond the scope of our paper, we must leave them as promising avenues for future research.

\section{REFERENCES}

Abeliansky, A., Martinez-Zarzoso, I., and Prettner, K. (2020). 3D Printing, International Trade, and FDI. Economic Modelling 85:288-306.

Acemoglu, D. (2009). Introduction to Modern Economic Growth. Princeton University Press, Princeton, NJ, USA.

Acemoglu, D. and Restrepo, P. (2017a). Secular Stagnation? The Effect of Aging on Economic Growth in the Age of Automation. American Economic Review, Papers \& Proceedings 107(5):174-179.

Acemoglu, D. and Restrepo, P. (2017b). Secular Stagnation? The Effect of Aging on Economic Growth in the Age of Automation. NBER Working Paper 23077.

Acemoglu, D. and Restrepo, P. (2018). The Race Between Man and Machine: Implications of Technology for Growth, Factor Shares and Employment. American Economic Review 108(6):1488-1542.

Acemoglu, D. and Restrepo, P. (2020). Robots and Jobs: Evidence from US Labor Markets. Journal of Political Economy 107(5):2188-2244.

Acemoglu, D. and Restrepo, P. (2021). Demographics and Automation. The Review of Economic Studies (forthcoming).

Anderson, T. W. and Hsiao, C. (1982). Formulation and estimation of dynamic models using panel data. Journal of Econometrics 18:47-82.

Antony, J. and Klarl, T. (2020). The implications of automation for economic growth when investment decisions are irreversible. Economics Letters 186:108757.

Arellano, M. and Bond, S. (1991). Some tests of specification for panel data: Monte Carlo evidence and an application to employment equations. Review of Economic Studies 58:277-297.

Arntz, M., Gregory, T., and Zierahn, U. (2017). Revisiting the risk of automation. Economics Letters 159:157-160.

Ashraf, Q., Weil, D., and Wilde, J. (2013). The effect of fertility reduction on economic growth. Population and Development Review 39(1):97-130.

Autor, D. (2002). Skill Biased Technical Change and Rising Inequality: What is the Evidence? What are the Alternatives? url: https ://economics .mit.edu/files/558. [accessed on 03/01/2018].

Autor, D. H. and Dorn, D. (2013). The Growth of Low-Skill Service Jobs and the Polarization of the US Labor Market. American Economic Review 103(5):1553-1597.

Barro, R. J. and Lee, J.-W. (2013). A New Data Set of Educational Attainment in the World, 1950-2010. Journal of Development Economics 104:184-198. 
Bloom, D. and Luca, D. (2016). The Global Demography of Aging: Facts, Explanations, Future. IZA Discussion Paper No. 10163.

Bloom, D. E., Canning, D., and Fink, G. (2010). Implications of Population Ageing for Economic Growth. Oxford Review of Economic Policy 26(4):583-612.

Bloom, D. E., Canning, D., Fink, G., and Finlay, J. (2009). Fertility, Female Labor Force Participation, and the Demographic Dividend. Journal of Economic Growth 14(2):79-101.

Bloom, D. E., Canning, D., Mansfield, R. K., and Moore, M. (2007). Demographic change, social security systems, and savings. Journal of Monetary Economics 54(1):92-114.

Blundell, R. and Bond, S. (1998). Initial conditions and moment restrictions in dynamic panel data methods. Journal of Econometrics 87:115-143.

Borghans, L. and ter Weel, B. (2002). Do older workers have more trouble using a computer than younger workers? The Economics of Skills Obsolescence 21:139-173.

Box, G. E. and Cox, D. R. (1964). An analysis of transformations. Journal of the Royal Statistical Society. Series B (Methodological), pages 211-252.

Bruno, G. S. F. (2005a). Approximating the bias of the LSDV estimator for dynamic unbalanced panel data models. Economics Letters 87:361-366.

Bruno, G. S. F. (2005b). Estimation and inference in dynamic unbalanced panel-data models with a small number of individuals. The Stata Journal 5(4):473-500.

Brynjolfsson, E. and McAfee, A. (2016). The Second Machine Age: Work, Progress, and Prosperity in a Time of Brilliant Technologies. Norton \& Company.

Busse, M. and Spielmann, C. (2006). Gender inequality and trade. Review of International Economics 14(3):362-379.

Canton, E., de Groot, H., and Hahuis, R. (2002). Vested interests, population ageing and technology adoption. European Journal of Political Economy 18(4):631-652.

Chu, A. C., Cozzi, G., Fan, H., Furukawa, Y., and Liao, C.-H. (2020). How Minimum Wages Affect Automationand Innovation in a Schumpeterian Economy. MPRA Paper No. 103974.

Cords, D. and Prettner, K. (2021). Technological Unemployment Revisited: Automation in a Search and Matching Framework. Oxford Economic Papers, (Forthcoming).

d'Albis, H., Boubtane, E., and Coulibaly, D. (2020). Demographic Changes and the Labor Income Share. HAL Id: halshs-02278765 https://halshs . archives-ouvertes.fr/halshs-02278765v2.

Dauth, W., Findeisen, S., Suedekum, J., and Woessner, N. (2017). German Robots - The Impact of Industrial Robots on Workers. CEPR Discussion Paper 12306.

Diamond, P. A. (1965). National debt in a neoclassical growth model. American Economic Review 55(5):1126-1150.

Elsby, M. W. L., Hobijn, B., and Şahin, A. (2013). The Decline of the U.S. Labor Share. Brookings Papers on Economic Activity, Fall 2013:1-63.

Frey, C. B. and Osborne, M. A. (2017). The future of employment: How susceptible are jobs to computerisation? Technological Forecasting and Social Change 114(Issue C):254-280.

Gasteiger, E. and Prettner, K. (2020). Automation, Stagnation, and the Implications of a Robot Tax. Macroeconomic Dynamics. (forthcoming).

Gehringer, A. and Prettner, K. (2019). Longevity and technological change. Macroeconomic Dynamics 23:1471-1503. 
Glover, A. and Short, J. (2020). Demographic Origins of the Decline in Labor's Share. BIS Working Papers 874, Bank for International Settlements.

Graetz, G. and Michaels, G. (2018). Robots at Work. The Review of Economics and Statistics 100(5):753-768.

Gregory, G., Salomons, A., and Zierahn, U. (2016). Racing With or Against the Machine? Evidence from Europe. ZEW Discussion Paper No. 16-053.

Grossmann, V., Steger, T. M., and Trimborn, T. (2013). Dynamically optimal R\&D subsidization. Journal of Economic Dynamics and Control 37:516-534.

Gruber, J. and Wise, D. (1998). Social security and retirement: an international comparison. American Economic Review 88(2):158-163.

Guimarães, L. and Mazeda Gil, P. (2019). Explaining the labor share: Automation vs labor market Institutions. MPRA Paper No. 92062.

Hémous, D. and Olsen, M. (2021). The Rise of the Machines: Automation, Horizontal Innovation and Income Inequality. American Economic Journal: Macroeconomics, (Forthcoming).

International Federation of Robotics (2015). Robot density: Top 10 countries with most industrial robots for every 10,000 people employed in manufacturing. Available at https://roboticsandautomationnews .com/2015/07/ 17 [Accessed at January 22, 2017].

International Federation of Robotics (2016). World Robotics Industrial Robots 2016.

Judson, R. A. and Owen, A. L. (1999). Estimating dynamic panel data models: a guide for macroeconomists. Economics Letters 65:9-15.

Karabarbounis, L. and Neiman, B. (2014). The Global Decline of the Labor Share. The Quarterly Journal of Economics 129(1):61-103.

Lanchester, J. (2015). The Robots Are Coming. London Review of Books 37(5):3-8.

Lankisch, C., Prettner, K., and Prskawetz, A. (2019). How can robots affect wage inequality? Economic Modelling 81:161-169.

Lee, R. and Mason, A. (2010). Fertility, Human Capital, and Economic Growth over the Demographic Transition. European Journal of Population 26(2):159-182.

Mankiw, G. N. and Weil, D. N. (1989). The Baby-Boom, the Baby-Bust and the Housing Market. Regional Science and Urban Economics 19:235-258.

Nickell, S. S. (1981). Biases in dynamic models with fixed effects. Econometrica 49:1117-1126.

Prettner, K. (2019). A note on the implications of automation for economic growth and the labor share. Macroeconomic Dynamics 23(3):1294-1301.

Prettner, K. and Bloom, D. (2020). Automation and Its Macroeconomic Consequences. Theory, Evidence, and Social Impacts. Academic Press, Cambridge, MA, USA.

Prettner, K. and Strulik, H. (2020). Innovation, Automation, and Inequality: Policy Challenges in the Race against the Machine. Journal of Monetary Economics 116:249-265.

Schich, S. (2008). Revistiting the asset-meltdown hypothesis. OECD Journal: Financial Market Trends 2008(2):209222.

Solow, R. M. (1956). A contribution to the theory of economic growth. The Quarterly Journal of Economics 70(1):65-94.

Steigum, E. (2011). Frontiers of Economics and Globalization: Economic Growth and Development, chapter 21: Robotics and Growth, pages 543-557. Emerald Group. 
Strulik, H., Prettner, K., and Prskawetz, A. (2013). The past and future of knowledge-based growth. Journal of Economic Growth 18(4):411-437.

The Economist (2011). 70 or bust! Why the retirement age must go up. A special report on pensions. The Economist, April 7th 2011.

The Economist (2014). Immigrants from the future. A special report on robots. The Economist, March 27th 2014.

The Economist (2019). Grandma's little helper. An ageing world needs more resourceful robots. February 14th, 2019.

The Washington Post (2016). Robots won't kill the workforce. They'll save the global economy. The Washington Post, December 2nd 2016.

United Nations (2015). World Population Prospects: The 2015 Revision. United Nations, Department of Economic and Social Affairs. Population Division, Population Estimates Section.

Weil, D. (1997). Handbook of Population and Family Economics, chapter The economics of population aging, pages 967-1014. Elsevier.

Whittaker, J., Whitehead, C., and Somers, M. (2005). The neglog transformation and quantile regression for the analysis of a large credit scoring database. Journal of the Royal Statistical Society: Series C (Applied Statistics) 54(5):863-878.

World Bank (2016). World Development Indicators \& Global Development Finance Database. Available at: http: //databank.worldbank.org/data/reports. aspx?source=world-development-indicators\#. 


\section{A APPENDIX}

\section{A.1 SUMMARY STATISTICS}

Table A.1: Summary statistics

\begin{tabular}{l|c|c|c|c|c}
\hline \hline Variable (in logs) & Observations & Mean & Std. Dev. & Minimum & Maximum \\
\hline$\hat{p}_{t-1}$ & 300 & 4.300 & 0.909 & -2.126 & 8.249 \\
$n_{t-1}$ & 300 & -2.057 & 0.239 & -2.788 & -1.179 \\
$s_{i ; t-1}$ & 300 & 2.879 & 0.609 & -1.697 & 3.815 \\
$y_{t-1}$ & 300 & 9.351 & 1.262 & 6.539 & 11.408 \\
$e_{t-1}$ & 267 & 4.368 & 0.540 & 1.616 & 5.065 \\
open $_{t-1}$ & 295 & 4.262 & 0.523 & 2.789 & 6.033 \\
\hline \hline
\end{tabular}

Table A.2: Countries included in the sample

\begin{tabular}{llll}
\hline \hline Argentina & France & Moldova & Serbia \\
Australia & Germany & Morocco & Singapore \\
Austria & Greece & NAFTA & Slovakia \\
Belgium & Hungary & Netherlands & South Africa \\
Brazil & Iceland & New Zealand & Spain \\
Bulgaria & India & Norway & Sweden \\
Chile & Indonesia & Oman & Switzerland \\
China & Ireland & Pakistan & Thailand \\
Colombia & Israel & Peru & Tunisia \\
Croatia & Italy & Philippines & Turkey \\
Czech Republic & Japan & Poland & Ukraine \\
Denmark & South Korea & Portugal & United Kingdom \\
Egypt & Kuwait & Romania & Uzbekistan \\
Estonia & Lithuania & Russia & Venezuela \\
Finland & Malaysia & Saudi Arabia & Vietnam \\
\hline \hline
\end{tabular}


A.2 COUNTRIES INCLUDED

Table A.3: Countries with values adjusted to create manufacturing stock

\begin{tabular}{ll|lc}
\hline \hline Country & Year & Country & Year \\
\hline Argentina & 2004 & South Korea & 2001 (gap in 2002) \\
Australia & 2006 & Malaysia & 2006 \\
Austria & 2003 & Mexico & 2011 \\
Belgium & 2004 & Netherlands & 2004 \\
Brazil & 2004 & New Zealand & 2006 \\
Bulgaria & 2006 & Philippines & 2006 \\
Canada & 2011 & Poland & 2004 \\
Chile & 2005 & Portugal & 2004 \\
China & 2006 & Romania & 2004 \\
Denmark & 1996 & Russia & 2004 \\
Greece & 2006 & Singapore & 2005 \\
Hungary & 2004 & Slovakia & 2004 \\
Iceland & 2006 & Slovenia & 2005 \\
Malta & 2006 & South Africa & 2005 \\
Peru & 2006 & Switzerland & 2004 \\
India & 2006 & Thailand & 2005 \\
Indonesia & 2006 & Turkey & 2005 \\
Ireland & 2006 & USA & 2004 \\
Israel & 2005 & Vietnam & 2005 \\
Japan & 1996 & & \\
\hline Note: :he year indicates the first time that the country reported disaggregated deliveries of robots at the \\
industry level.
\end{tabular}


Table A.4: Description of variables used in the empirical analysis

\begin{tabular}{|c|c|c|}
\hline Variable & Source & Construction of variables used in the empirical regression \\
\hline Robots & International Federation of Robotics & $\begin{array}{l}\text { The variable is standardised by population. Next, we calculate the growth rate. Later, we use the zero-skewness log transformation. This allows us to smooth the variable in a similar vein } \\
\text { to a log transformation, but includes the negative values and zeroes. Not all countries report the stock or the deliveries of industrial robots disaggregated at the industry level on a yearly } \\
\text { basis. We follow Graetz and Michaels (2018) and take the average share of manufacturing robots over the total deliveries of robots (when the data were available), construct an } \\
\text { average share, and impute the values for manufacturing robot deliveries, as well as for the initial stock of robots (when the corresponding data were not available). } \\
\text { Please see Table A.2. in the Appendix for further details. Using the initial value of the stock of industrial robots we create the stock of robots using the perpetual inventory method and } \\
\text { assume a depreciation rate of } 10 \text { percent. }\end{array}$ \\
\hline Population & World Development Indicators & $\begin{array}{l}\text { Total population. We calculate the growth rate. Later we use the zero-skewness log transformation. This allows us to smooth the variable in a similar vein to a log transformation but } \\
\text { includes the negative values and zeroes. }\end{array}$ \\
\hline Saving Rate & International Monetary Fund & $\begin{array}{l}\text { Since we are not able to find a comprehensive dataset on saving rate we instead use the investment share over GDP. We sum the reported values of private investment, public investment, } \\
\text { and joint ventures between the state and the private sector. We take logs. }\end{array}$ \\
\hline GDP per Capita & World Development Indicators & GDP per capita measured in constant $\$$ USD with a base year of 2010 . We take logs. \\
\hline & World Development Indicators & Openness is measured as exports and imports over GDP. W \\
\hline Education & World Development Indicators & Gross enrolment ratio in secondary schools. We take logs. \\
\hline Service Sector & World Development Indicators & Contribution of the service sector to total GDP. We take logs. \\
\hline pital Formation & $\begin{array}{l}\text { Penn World Tables } \\
\text { World Development Indicators }\end{array}$ & $\begin{array}{l}\text { Capital stock measured in } 2005 \$ \text { USD. We take logs. } \\
\text { Gross fixed capital formation as a fraction of GDP. We take logs. }\end{array}$ \\
\hline Labour Force & World Development Indicators & $\begin{array}{l}\text { Labour force. Next, we calculate the growth rate. Later, we use the zero-skewness log transformation. This allows us to smooth the variable in a similar vein to a log transformation, but } \\
\text { includes the negative values and zeroes. }\end{array}$ \\
\hline Life Expectancy & World Development Indicators & $\begin{array}{l}\text { "Life expectancy at birth indicates the number of years a newborn infant would live if prevailing patterns of mortality at the time of its birth were to stay the same throughout its life" } \\
\text { (metadata description). We take logs. }\end{array}$ \\
\hline Robot Exports & UN COMTRADE & $\begin{array}{l}\text { We consider the code } 847950 \text { (HS96) for the data, divide it by GDP, and use the zero-skewness log transformation. This allows us to smooth the variable in a similar vein to a log } \\
\text { transformation, but includes the zero values. }\end{array}$ \\
\hline Dependency Ratio & World Development Indicators & $\begin{array}{l}\text { Age dependency ratio is the ratio of dependents-people younger than } 15 \text { or older than } 64 \text {-to the working-age population-those ages 15-64. Data are shown as the proportion of dependents } \\
\text { per } 100 \text { working-age population (metadata description). We take logs. }\end{array}$ \\
\hline
\end{tabular}




\section{A.3 DISTRIBUTION OF THE MANUFACTURING STOCK OF ROBOTS}

Figure A.1: Average manufacturing robot density for the period 1993-1995

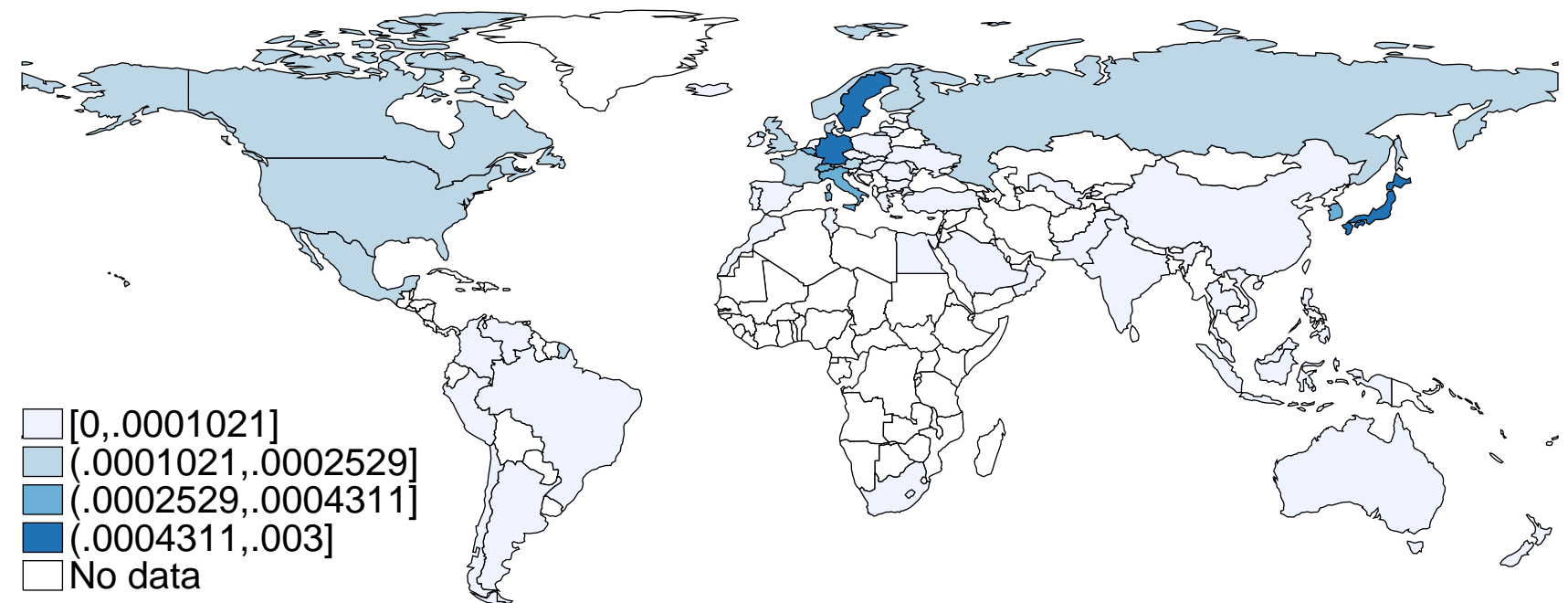

Source: IFR and World Development Indicators. Note: The USA, Canada, and Mexico have the same values because of joint reporting.

Figure A.2: Average manufacturing robot density in the period 2011-2013

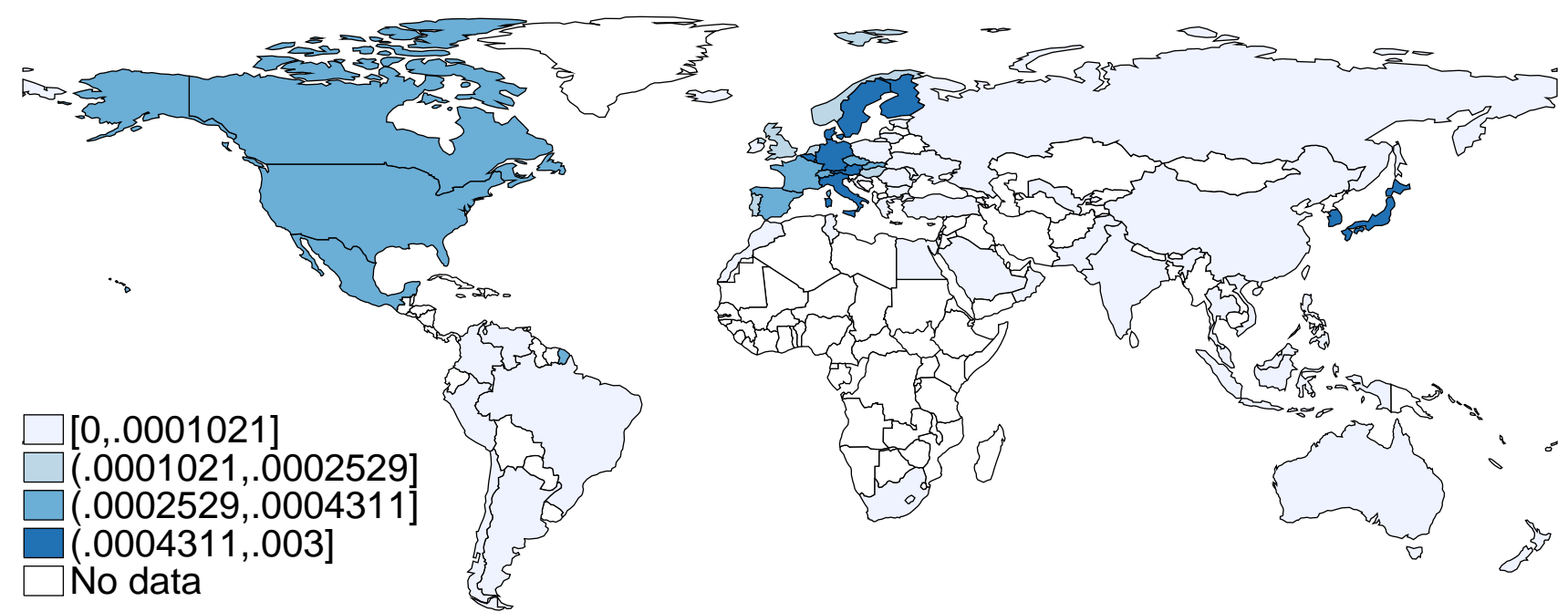

Source: IFR and World Development Indicators. Note: The USA, Canada, and Mexico have the same values because of joint reporting. 
A.4 SAVING RATE AND POPULATION GROWTH

Table A.5: Saving rate and population growth, same period

\begin{tabular}{|c|c|c|c|c|c|c|c|}
\hline & $\begin{array}{c}(1) \\
\text { POLS }\end{array}$ & $\begin{array}{l}(2) \\
\mathrm{RE}\end{array}$ & $\begin{array}{l}(3) \\
\mathrm{FE}\end{array}$ & $\begin{array}{c}(4) \\
\text { CorrFE (bb) }\end{array}$ & $\begin{array}{c}(5) \\
\text { CorrFE }(a b)\end{array}$ & $\begin{array}{c}\text { (6) } \\
\text { CorrFE (ah) }\end{array}$ & $\begin{array}{c}\text { (7) } \\
\text { GMM (sys) }\end{array}$ \\
\hline$s_{t-1}$ & & & & $\begin{array}{c}0.673^{* * *} \\
(0.039)\end{array}$ & $\begin{array}{c}0.573^{* * *} \\
(0.043)\end{array}$ & $\begin{array}{c}0.581^{* * *} \\
(0.044)\end{array}$ & $\begin{array}{c}0.779^{* * *} \\
(0.132)\end{array}$ \\
\hline$n_{t}$ & $\begin{array}{l}0.712^{* *} \\
(0.326)\end{array}$ & $\begin{array}{c}0.426^{* * *} \\
(0.153)\end{array}$ & $\begin{array}{l}0.387^{* *} \\
(0.172)\end{array}$ & $\begin{array}{c}0.125 \\
(0.119)\end{array}$ & $\begin{array}{c}0.152 \\
(0.102)\end{array}$ & $\begin{array}{c}0.150 \\
(0.103)\end{array}$ & $\begin{array}{c}0.126 \\
(0.164)\end{array}$ \\
\hline Country FE & no & no & yes & yes & yes & yes & yes \\
\hline Time FE & yes & yes & yes & yes & yes & yes & yes \\
\hline $\mathrm{AR}(2)$ test & & - & - & - & - & - & 0.637 \\
\hline Hansen Test & & - & - & - & - & - & 0.126 \\
\hline Countries & 60 & 60 & 60 & 60 & 60 & 60 & 60 \\
\hline Observations & 300 & 300 & 300 & 300 & 300 & 300 & 300 \\
\hline
\end{tabular}

Note: Standard errors in parenthesis. ${ }^{* * *}, * *$ and $*$ indicate significance at the 1,5 , and 10 percent level, respectively. The standard errors in columns (1), (2), and (3) are clustered at the country level, while those from (4) to (6) are bootstrapped with 50 iterations. Column (7) uses collapsed instruments and an orthogonal transformation. All of the variables are in logarithms, while population growth was transformed with the zero-skewness log transformation. CorrFE refers to the corrected fixed effects with $b b$ indicating initialisation by the Blundell and Bond (1998) estimator, $a b$ initialisation by Arellano and Bond (1991) estimator, and $a h$ initialisation by the Anderson and Hsiao (1982) estimator, $s_{i, t-1}$ is the gross investment rate in period $t-1$, and $n_{i, t-1}$ is the population growth rate between periods $t-1$ and $t-2$. 


\section{A.5 ROBUSTNESS ANALYSIS}

As a first robustness check, we control for three potential omitted variables: GDP per capita, openness of the economy, and secondary school enrolment. Omitting these variables could be a source of bias for the following reasons. As far as GDP per capita is concerned, richer countries are better able to invest in new technologies and are also those that are disproportionally affected by declining fertility as outlined in Section. As far as openness is concerned, an open economy might be under more pressure to stay competitive, while smaller economies (by population size) tend to be more open. Finally, education has a negative effect on fertility and a positive effect on GDP per capita, while, at the same time, a better educated population might be more inclined to invest in (or adapt to) robots.

Table A.6, which includes the mentioned control variables, again shows a negative correlation between robot density growth and population growth. The magnitude of the coefficients in the different specifications are marginally smaller than in the previous tables. However, except for the pooled OLS specification, they are statistically significant at the 5 percent or at the 10 percent level. One reason for the lower significance levels might be that we have to accept a reduction in the sample size because of several missing observations for the openness and the secondary enrolment variables. The coefficient estimate of the investment rate is still not statistically significant across the specifications, as in the previous case. In columns (1) and (2), GDP per capita has a negative sign, which is surprising given that richer countries would be able to invest more in new technologies. However, GDP per capita reverts its sign from column (3) onwards. Again, we believe that the reason for this is the presence of unobserved heterogeneity correlated with the regressors and therefore the estimation of a misspecified regression in columns (1) and (2), as also suggested by the Hausman test. Secondary enrolment has the predicted sign, although it is not statistically significant. Openness has a negative sign in most of the specifications, although none of the coefficients are statistically significant. Moreover, the coefficient size of the lagged dependent variable shows no need for taking the dynamics into account in the regressions.

Table A.6: Total robots growth including controls

\begin{tabular}{lccccccc}
\hline \hline \multirow{5}{*}{} & $(1)$ & $(2)$ & $(3)$ & $(4)$ & $(5)$ & $(6)$ & $(7)$ \\
& POLS & RE & FE & CorrFE (bb) & CorrFE (ab) & CorrFE (ah) & GMM (sys) \\
\hline$\hat{p}_{t-1}$ & & & & & & & \\
& & & & $0.210^{* *}$ & 0.137 & 0.140 & 0.279 \\
$n_{t-1}$ & -0.565 & $-0.731^{*}$ & $-1.554^{* *}$ & $-1.377^{*}$ & $-1.494^{* *}$ & $-1.485^{* *}$ & $-3.247^{*}$ \\
& $(0.379)$ & $(0.422)$ & $(0.689)$ & $(0.754)$ & $(0.704)$ & $(0.708)$ & $(1.879)$ \\
$s_{t-1}$ & 0.092 & 0.107 & -0.416 & -0.377 & -0.337 & -0.336 & -0.316 \\
& $(0.130)$ & $(0.134)$ & $(0.556)$ & $(0.486)$ & $(0.443)$ & $(0.445)$ & $(0.485)$ \\
$y_{t-1}$ & $-0.172^{* *}$ & $-0.151^{* *}$ & $2.535^{* * *}$ & $2.316^{* * *}$ & $2.280^{* * *}$ & $2.283^{* * *}$ & -0.080 \\
& $(0.073)$ & $(0.073)$ & $(0.911)$ & $(0.883)$ & $(0.784)$ & $(0.787)$ & $(0.421)$ \\
$e_{t-1}$ & 0.148 & 0.133 & 0.112 & 0.106 & 0.111 & 0.111 & 0.334 \\
& $(0.180)$ & $(0.176)$ & $(0.192)$ & $(0.185)$ & $(0.171)$ & $(0.171)$ & $(0.244)$ \\
open $n_{t-1}$ & 0.040 & 0.034 & -0.088 & -0.149 & -0.136 & -0.139 & -0.144 \\
& $(0.142)$ & $(0.155)$ & $(0.519)$ & $(0.552)$ & $(0.503)$ & $(0.506)$ & $(0.795)$ \\
& & & & & & & \\
& & & & & & & \\
\hline Country FE & no & no & yes & yes & yes & yes & - \\
Time FE & yes & yes & yes & yes & yes & yes & yes \\
AR(2) test & - & - & - & - & - & - & 0.979 \\
Hansen test & - & - & - & - & - & - & 0.156 \\
Countries & 57 & 57 & 57 & 57 & 57 & 57 & 57 \\
Observations & 262 & 262 & 262 & 262 & 262 & 262 & 262 \\
\hline \hline
\end{tabular}

Note: Standard errors in parenthesis. ${ }^{* * *},{ }^{* *}$, and ${ }^{*}$ indicate significance at the 1,5 , and 10 percent level, respectively. The standard errors in columns (1), (2), and (3) are clustered at the country level, while those from (4) to (6) are bootstrapped with 50 iterations. Column (7) uses collapsed instruments and an orthogonal transformation. All of the variables are in logarithms, while population growth and robots growth were transformed with the zero-skewness log transformation. CorrFE refers to the corrected fixed effects with $b b$ indicating initialisation by the Blundell and Bond (1998) estimator, $a b$ initialisation by Arellano and Bond (1991) estimator, and $a h$ initialisation by the Anderson and Hsiao (1982) estimator. $\hat{p}_{t-1}$ is the growth rate of the robot density (either manufacturing robots, or the total amount of robots per 1000 inhabitants) between periods $t-1$ and $t-2, n_{i, t-1}$ is the population growth rate between periods $t-1$ and $t-2, s_{i, t-1}$ is the gross investment rate in period $t-1, y_{t-1}$ is GDP per capita in $t-1$, open $_{t-1}$ is openness in $t-1$, and $e_{t-1}$ is secondary school enrolment in $t-1$. 
Table A.7: Manufacturing robots growth including controls

\begin{tabular}{lccccccc}
\hline \hline \multirow{5}{*}{} & $(1)$ & $(2)$ & $(3)$ & $(4)$ & $(5)$ & $(6)$ & $(7)$ \\
& POLS & RE & FE & CorrFE (bb) & CorrFE (ab) & CorrFE (ah) & GMM (sys) \\
\hline$\hat{p}_{t-1}$ & & & & & & & \\
& & & & $0.148^{*}$ & 0.064 & 0.60 & 0.043 \\
$n_{t-1}$ & -0.472 & -0.636 & $-1.726^{* *}$ & $-1.599^{* *}$ & $-1.700^{* *}$ & $-1.697^{* *}$ & -1.833 \\
& $(0.382)$ & $(0.422)$ & $(0.702)$ & $(0.771)$ & $(0.703)$ & $(0.706)$ & $(1.218)$ \\
$s_{t-1}$ & 0.061 & 0.067 & -0.646 & -0.586 & -0.567 & -0.570 & -0.241 \\
& $(0.109)$ & $(0.108)$ & $(0.558)$ & $(0.496)$ & $(0.441)$ & $(0.442)$ & $(0.349)$ \\
$y_{t-1}$ & $-0.197^{* * *}$ & $-0.181^{* * *}$ & $2.617^{* * *}$ & $2.531^{* * *}$ & $2.551^{* * *}$ & $2.580^{* * *}$ & $-0.523^{* * * *}$ \\
& $(0.068)$ & $(0.067)$ & $(0.841)$ & $(0.899)$ & $(0.785)$ & $(0.787)$ & $(0.169)$ \\
$e_{t-1}$ & 0.187 & 0.182 & 0.174 & 0.171 & 0.174 & 0.173 & $0.352^{*}$ \\
& $(0.175)$ & $(0.166)$ & $(0.174)$ & $(0.189)$ & $(0.171)$ & $(0.171)$ & $(0.180)$ \\
open $n_{t-1}$ & 0.024 & 0.021 & 0.000 & -0.059 & -0.033 & -0.036 & -0.392 \\
& $(0.148)$ & $(0.158)$ & $(0.515)$ & $(0.566)$ & $(0.504)$ & $(0.507)$ & $(0.659)$ \\
& & & & & & & \\
\hline Country FE & no & no & yes & yes & yes & yes & - \\
Time FE & yes & yes & yes & yes & yes & yes & yes \\
AR(2) test & - & - & - & - & - & - & 0.720 \\
Hansen test & - & - & - & - & - & - & 0.234 \\
Countries & 57 & 57 & 57 & 57 & 57 & 57 & 57 \\
Observations & 262 & 262 & 262 & 262 & 262 & 262 & 262 \\
\hline \hline
\end{tabular}

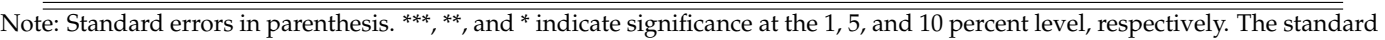
errors in columns (1), (2), and (3) are clustered at the country level, while those from (4) to (6) are bootstrapped with 50 iterations. Column (7) uses collapsed instruments and an orthogonal transformation. All of the variables are in logarithms, while population growth and robots growth were transformed with the zero-skewness log transformation. CorrFE refers to the corrected fixed effects with $b b$ indicating initialisation by the Blundell and Bond (1998) estimator, $a b$ initialisation by Arellano and Bond (1991) estimator, and $a h$ initialisation by the Anderson and Hsiao (1982) estimator. $\hat{p}_{t-1}$ is the growth rate of the robot density (either manufacturing robots, or the total amount of robots per 1000 inhabitants) between periods $t-1$ and $t-2, n_{i, t-1}$ is the population growth rate between periods $t-1$ and $t-2, s_{i, t-1}$ is the gross investment rate in period $t-1, y_{t-1}$ is GDP per capita in $t-1$, open $_{t-1}$ is openness in $t-1$, and $e_{t-1}$ is secondary school enrolment in $t-1$. 
Turning to the results regarding manufacturing robots as displayed in Table A.7, we observe a similar pattern as with the total amount of robots. All specifications show a negative correlation between manufacturing robot density growth and population growth. In contrast to the previous results, we find no statistical significance in case of the system GMM estimator reported in column (7). However, this could be related to the fact that the system GMM estimator is inefficient for a small time dimension. As in the previous tables, we find no evidence concerning the importance of investment or secondary schooling for robot adoption. Like the total stock of robots, we find a positive relationship between GDP per capita and the growth rate of the manufacturing robot density. A puzzling result is the change in the sign of per capita GDP in case of the system GMM estimator. However, the estimations performed with the corrected fixed effects estimators still exhibit a significantly positive coefficient estimate.

Tables A.8 and A.9 report the same specification as before, but omit the controls that were not statistically significant (i.e., secondary school enrolment and openness). The results do not change dramatically but the significance of the puzzling negative sign of per capita GDP in case of the system GMM estimator vanishes. Additionally, we report the results from adding the $(\log )$ of the size of the service sector as a percentage of overall value added to control for structural change. The results remain fairly unchanged (see Table A.10 for total robots and Table A.11 for manufacturing robots). As alternatives to the saving rate, we used two different proxies for investment - the capital stock (in 2005 \$ US) from the Penn World Tables version 8.1 and gross fixed capital formation as a fraction of GDP from the World Development Indicators. Tables A.12 and A.14 show the results for the total stock of robots, while Tables A.13 and A.15 show the results for the manufacturing robots only. The tables show that the stock of capital is not significantly correlated with the pace of robot adoption. Moreover, the estimates of population growth remain close in value to our previous estimates and statistically significant in the relevant specifications. The same conclusion holds when we include alternative controls such as the dependency ratio, the stock of exported robots, and life expectancy (results available in Tables A.16 and A.17 for total robots and manufacturing robots, respectively).

Table A.8: Total robots growth including GDP per capita

\begin{tabular}{|c|c|c|c|c|c|c|c|}
\hline & $\begin{array}{c}(1) \\
\text { POLS }\end{array}$ & $\begin{array}{l}(2) \\
R E\end{array}$ & $\begin{array}{l}(3) \\
\mathrm{FE}\end{array}$ & $\begin{array}{c}(4) \\
\text { CorrFE (bb) }\end{array}$ & $\begin{array}{c}\text { (5) } \\
\text { CorrFE (ab) }\end{array}$ & $\begin{array}{c}\text { (6) } \\
\text { CorrFE (ah) }\end{array}$ & $\begin{array}{c}\text { (7) } \\
\text { GMM (sys) }\end{array}$ \\
\hline$\hat{p}_{t-1}$ & & & & $\begin{array}{c}0.250^{* * *} \\
(0.079)\end{array}$ & $\begin{array}{l}0.197^{* *} \\
(0.092)\end{array}$ & $\begin{array}{l}0.197^{* *} \\
(0.100)\end{array}$ & $\begin{array}{c}0.119 \\
(0.163)\end{array}$ \\
\hline$n_{t-1}$ & $\begin{array}{l}-0.601^{*} \\
(0.320)\end{array}$ & $\begin{array}{c}-0.732^{* *} \\
(0.345)\end{array}$ & $\begin{array}{l}-1.444^{*} \\
(0.758)\end{array}$ & $\begin{array}{l}-1.283^{*} \\
(0.659)\end{array}$ & $\begin{array}{c}-1.430^{* *} \\
(0.611)\end{array}$ & $\begin{array}{c}-1.421^{* *} \\
(0.607)\end{array}$ & $\begin{array}{c}0.565 \\
(8.093)\end{array}$ \\
\hline$s_{t-1}$ & $\begin{array}{c}0.102 \\
(0.143)\end{array}$ & $\begin{array}{c}0.123 \\
(0.148)\end{array}$ & $\begin{array}{c}0.003 \\
(0.557)\end{array}$ & $\begin{array}{l}-0.006 \\
(0.400)\end{array}$ & $\begin{array}{c}0.053 \\
(0.374)\end{array}$ & $\begin{array}{c}0.052 \\
(0.374)\end{array}$ & $\begin{array}{c}0.003 \\
(0.420)\end{array}$ \\
\hline$y_{t-1}$ & $\begin{array}{c}-0.137^{* * *} \\
(0.049)\end{array}$ & $\begin{array}{c}-0.131^{* * *} \\
(0.048)\end{array}$ & $\begin{array}{c}2.195^{* * *} \\
(0.817)\end{array}$ & $\begin{array}{l}1.944^{* *} \\
(0.800)\end{array}$ & $\begin{array}{l}1.855^{* *} \\
(0.737)\end{array}$ & $\begin{array}{l}1.872^{* *} \\
(0.735)\end{array}$ & $\begin{array}{c}-0.554 \\
(1.130)\end{array}$ \\
\hline Country FE & no & no & yes & yes & yes & yes & - \\
\hline Year FE & yes & yes & yes & yes & yes & yes & yes \\
\hline $\mathrm{AR}(2)$ test & - & - & - & - & - & - & 0.438 \\
\hline Hansen test & - & - & - & - & - & - & 0.591 \\
\hline Countries & 60 & 60 & 60 & 60 & 60 & 60 & 60 \\
\hline Observations & 300 & 300 & 300 & 300 & 300 & 300 & 300 \\
\hline $\begin{array}{l}\text { andard errors in } p \\
\text { (1), (2), and (3) ar } \\
\text { dinstruments and } \\
\text { snformed with the } \\
\text { and Bond (1998) } \\
\text { timator. } \hat{p}_{t-1} \text { is } \\
\text { periods } t-1 \text { and } \\
-1 \text {, and } y\end{array}$ & $\begin{array}{l}\text { arenthesis. } \\
\text { re clustered at } \\
\text { an orthogona } \\
\text { zero-skewnes } \\
\text { estimator, } a b \text { i } \\
\text { the growth ra } \\
t-2, n_{i, t-1} \\
\text { DP per capita }\end{array}$ & $\begin{array}{l}\text { F }^{* *} \text {, and }{ }^{*} \text { in } \\
\text { the country } \\
\text { transformat } \\
\text { log transfor } \\
\text { itialisation b } \\
\text { of robot de } \\
\text { sthe popula } \\
\text { in } t-1 \text {. }\end{array}$ & $\begin{array}{l}\text { licate signif } \\
\text { level, while } \\
\text { ion. All of } t \\
\text { mation. Cor } \\
\text { y Arellano } \\
\text { nsity (either } \\
\text { tion growth }\end{array}$ & $\begin{array}{l}\text { cance at the } 1,5 \\
\text { those from }(4) \text { to } \\
\text { ev variables are } \\
\text { FE refers to the c } \\
\text { nd Bond (1991) } \\
\text { manufacturing } \\
\text { rate between pe }\end{array}$ & $\begin{array}{l}\text { and } 10 \text { percent } \\
\text { (6) are bootstrar } \\
\text { logarithms, wh } \\
\text { rrected fixed eff } \\
\text { timator, and ah } \\
\text { bots, or the tota } \\
\text { ods } t-1 \text { and } t \text { - }\end{array}$ & $\begin{array}{l}\text { vel, respectively. } \\
\text { ped with } 50 \text { itera } \\
\text { le population gro } \\
\text { cts with } b b \text { indica } \\
\text { nitialisation by th } \\
\text { amount of robo } \\
2, s_{i, t-1} \text { is the }\end{array}$ & $\begin{array}{l}\text { The standard } \\
\text { tions. Column } \\
\text { wth and robots } \\
\text { ing initialisatic } \\
\text { ee Anderson an } \\
\text { s per } 1000 \text { inh } \\
\text { ross investmer }\end{array}$ \\
\hline
\end{tabular}


Table A.9: Manufacturing robots growth including GDP per capita

\begin{tabular}{|c|c|c|c|c|c|c|c|}
\hline & $\begin{array}{l}(1) \\
\text { POLS }\end{array}$ & $\begin{array}{l}(2) \\
R E\end{array}$ & $\begin{array}{l}(3) \\
\mathrm{FE}\end{array}$ & $\begin{array}{c}(4) \\
\text { CorrFE (bb) }\end{array}$ & $\begin{array}{c}\text { (5) } \\
\text { CorrFE (ab) }\end{array}$ & $\begin{array}{c}\text { (6) } \\
\text { CorrFE (ah) }\end{array}$ & $\begin{array}{c}\text { (7) } \\
\text { GMM (sys) }\end{array}$ \\
\hline$\hat{p}_{t-1}$ & & & & $\begin{array}{l}0.186^{* *} \\
(0.078)\end{array}$ & $\begin{array}{c}0.124 \\
(0.087)\end{array}$ & $\begin{array}{c}0.119 \\
(0.091)\end{array}$ & $\begin{array}{c}0.005 \\
(0.082)\end{array}$ \\
\hline$n_{t-1}$ & $\begin{array}{c}-0.525 \\
(0.326)\end{array}$ & $\begin{array}{c}-0.667^{*} \\
(0.355)\end{array}$ & $\begin{array}{l}-1.554^{*} \\
(0.806)\end{array}$ & $\begin{array}{c}-1.468^{* *} \\
(0.674)\end{array}$ & $\begin{array}{c}-1.587^{* * *} \\
(0.614)\end{array}$ & $\begin{array}{c}-1.577^{* * * *} \\
(0.612)\end{array}$ & $\begin{array}{c}0.466 \\
(4.403)\end{array}$ \\
\hline$s_{t-1}$ & $\begin{array}{c}0.069 \\
(0.119)\end{array}$ & $\begin{array}{c}0.080 \\
(0.120)\end{array}$ & $\begin{array}{l}-0.272 \\
(0.533)\end{array}$ & $\begin{array}{l}-0.229 \\
(0.409)\end{array}$ & $\begin{array}{l}-0.191 \\
(0.376)\end{array}$ & $\begin{array}{l}-0.197 \\
(0.376)\end{array}$ & $\begin{array}{c}0.020 \\
(0.476)\end{array}$ \\
\hline$y_{t-1}$ & $\begin{array}{c}-0.152^{* * * *} \\
(0.046)\end{array}$ & $\begin{array}{c}-0.145^{* * *} \\
(0.046)\end{array}$ & $\begin{array}{c}2.365^{* * *} \\
(0.717)\end{array}$ & $\begin{array}{l}2.221^{* * *} \\
(0.815)\end{array}$ & $\begin{array}{l}2.174^{* * *} \\
(0.740)\end{array}$ & $\begin{array}{c}2.215^{* * *} \\
(0.739)\end{array}$ & $\begin{array}{l}-0.626 \\
(0.511)\end{array}$ \\
\hline Country FE & no & no & yes & yes & yes & yes & - \\
\hline Year FE & yes & yes & yes & yes & yes & yes & yes \\
\hline $\mathrm{AR}(2)$ test & - & - & - & - & - & - & 0.250 \\
\hline Hansen test & - & - & - & - & - & - & 0.427 \\
\hline Countries & 60 & 60 & 60 & 60 & 60 & 60 & 60 \\
\hline Observations & 300 & 300 & 300 & 300 & 300 & 300 & 300 \\
\hline
\end{tabular}

Note: Standard errors in parenthesis. ${ }^{* * *}$, **, and ${ }^{*}$ indicate significance at the 1,5 , and 10 percent level, respectively. The standard errors in columns (1), (2), and (3) are clustered at the country level, while those from (4) to (6) are bootstrapped with 50 iterations. Column (7) uses collapsed instruments and an orthogonal transformation. All of the variables are in logarithms, while population growth and robots growth were transformed with the zero-skewness log transformation. Corre refers to the corrected fixed effects with bb indicating initialisation by the (1982) (1982) estimator. $\hat{p}_{t-1}$ is the growth rate of robot density (either manufacturing robots, or the total amount of robots per 1000 inhabitants) period $t-1$, and $y_{t-1}$ is GDP per capita in $t-1$.

Table A.10: Total robots growth including the service sector

\begin{tabular}{|c|c|c|c|c|c|c|c|}
\hline & $\begin{array}{c}(1) \\
\text { POLS }\end{array}$ & $\begin{array}{l}(2) \\
\mathrm{RE}\end{array}$ & $\begin{array}{l}(3) \\
\mathrm{FE}\end{array}$ & $\begin{array}{c}\text { (4) } \\
\text { CorrFE (bb) }\end{array}$ & $\begin{array}{c}\text { (5) } \\
\text { CorrFE (ab) }\end{array}$ & $\begin{array}{c}\text { (6) } \\
\text { CorrFE (ah) }\end{array}$ & $\begin{array}{c}\text { (7) } \\
\text { GMM (sys) }\end{array}$ \\
\hline$\hat{p}_{t-1}$ & & & & $\begin{array}{c}0.314^{* * *} \\
(.083)\end{array}$ & $\begin{array}{c}0.267^{* * *} \\
(.089)\end{array}$ & $\begin{array}{c}0.252^{* * *} \\
(0.090)\end{array}$ & $\begin{array}{c}0.159 \\
(0.146)\end{array}$ \\
\hline$n_{t-1}$ & $\begin{array}{l}-0.470 \\
(0.320)\end{array}$ & $\begin{array}{l}-0.594^{*} \\
(0.347)\end{array}$ & $\begin{array}{l}-1.907^{*} \\
(1.137)\end{array}$ & $\begin{array}{c}-1.617^{* *} \\
(0.774)\end{array}$ & $\begin{array}{c}-1.699 * * \\
(0.719)\end{array}$ & $\begin{array}{c}-1.726^{* *} \\
(0.724)\end{array}$ & $\begin{array}{l}-2.330 \\
(1.727)\end{array}$ \\
\hline$s_{t-1}$ & $\begin{array}{c}0.067 \\
(0.132)\end{array}$ & $\begin{array}{c}0.097 \\
(0.146)\end{array}$ & $\begin{array}{c}0.590 \\
(0.443)\end{array}$ & $\begin{array}{c}0.446 \\
(0.370)\end{array}$ & $\begin{array}{c}0.466 \\
(0.355)\end{array}$ & $\begin{array}{c}0.478 \\
(0.357)\end{array}$ & $\begin{array}{c}0.626 \\
(0.763)\end{array}$ \\
\hline $\operatorname{serv}_{t-1}$ & $\begin{array}{c}-0.590 \\
(0.596)\end{array}$ & $\begin{array}{c}-0.533 \\
(0.675)\end{array}$ & $\begin{array}{c}1.155 \\
(1.911)\end{array}$ & $\begin{array}{c}0.931 \\
(1.006)\end{array}$ & $\begin{array}{c}0.972 \\
(0.943)\end{array}$ & $\begin{array}{c}1.004 \\
(0.943)\end{array}$ & $\begin{array}{c}-3.872^{* *} \\
(1.759)\end{array}$ \\
\hline Country FE & no & no & yes & yes & yes & yes & - \\
\hline Year FE & yes & yes & yes & yes & yes & yes & yes \\
\hline $\mathrm{AR}(2)$ test & - & - & - & - & - & - & 0.957 \\
\hline Hansen test & - & - & - & - & - & - & 0.443 \\
\hline Countries & 58 & 58 & 58 & 58 & 58 & 58 & 58 \\
\hline Observations & 288 & 288 & 288 & 288 & 288 & 288 & 288 \\
\hline
\end{tabular}

Note: Standard errors in parenthesis. ${ }^{* * *}, * *$, and ${ }^{*}$ indicate significance at the 1,5 , and 10 percent level, respectively. The standard errors in columns (1), (2), and (3) are clustered at the country level, while those from (4) to (6) are bootstrapped with 50 iterations. Column (7) uses collapsed instruments and an orthogonal transformation. All of the variables are in logarithms, while population growth and robots growth were transformed with the zero-skewness $\log$ transformation. CorrFE refers to the corrected fixed effects with $b b$ indicating initialisation by the Blundell and Bond (1998) estimator, $a b$ initialisation by Arellano and Bond (1991) estimator, and $a h$ initialisation by the Anderson and Hsiao (1982) estimator. $\hat{p}_{t-1}$ is the growth rate of robot density (either manufacturing robots, or the total amount of robots per 1000 inhabitants) between $p e r$ en period $t-1$, and $\operatorname{serv}_{t-1}$ stands for the contribution of the service sector to overall GDP in $t-1$.

Table A.11: Manufacturing robots growth including the service sector

\begin{tabular}{|c|c|c|c|c|c|c|c|}
\hline & $\begin{array}{c}(1) \\
\text { POLS }\end{array}$ & $\begin{array}{l}\text { (2) } \\
\text { RE }\end{array}$ & $\begin{array}{l}\text { (3) } \\
\text { FE }\end{array}$ & $\begin{array}{c}(4) \\
\text { CorrFE (bb) }\end{array}$ & $\begin{array}{c}(5) \\
\text { CorrFE }(a b)\end{array}$ & $\begin{array}{c}(6) \\
\text { CorrFE (ah) }\end{array}$ & $\begin{array}{c}\text { (7) } \\
\text { GMM (sys) }\end{array}$ \\
\hline$\hat{p}_{t-1}$ & & & & $\begin{array}{c}0.342^{* * *} \\
(0.076)\end{array}$ & $\begin{array}{c}0.328^{* * *} \\
(.074)\end{array}$ & $\begin{array}{c}0.306^{* * *} \\
(0.078)\end{array}$ & $\begin{array}{c}0.047 \\
(0.121)\end{array}$ \\
\hline$n_{t-1}$ & $\begin{array}{l}-0.405 \\
(0.300)\end{array}$ & $\begin{array}{c}-0.516 \\
(0.323)\end{array}$ & $\begin{array}{l}-2.286^{*} \\
(1.257)\end{array}$ & $\begin{array}{c}-1.774^{* *} \\
(0.795)\end{array}$ & $\begin{array}{c}-1.790^{* *} \\
(0.769)\end{array}$ & $\begin{array}{c}-1.854^{* *} \\
(0.775)\end{array}$ & $\begin{array}{c}-4.526^{* *} \\
(2.291)\end{array}$ \\
\hline$s_{t-1}$ & $\begin{array}{c}0.033 \\
(0.103)\end{array}$ & $\begin{array}{c}0.050 \\
(0.112)\end{array}$ & $\begin{array}{c}0.370 \\
(0.423)\end{array}$ & $\begin{array}{c}0.187 \\
(0.375)\end{array}$ & $\begin{array}{c}0.194 \\
(0.366)\end{array}$ & $\begin{array}{c}0.209 \\
(0.367)\end{array}$ & $\begin{array}{c}1.023 \\
(1.010)\end{array}$ \\
\hline $\operatorname{serv}_{t-1}$ & $\begin{array}{c}-0.559 \\
(0.577)\end{array}$ & $\begin{array}{l}-0.535 \\
(0.636)\end{array}$ & $\begin{array}{c}1.010 \\
(1.893)\end{array}$ & $\begin{array}{c}0.830 \\
(1.022)\end{array}$ & $\begin{array}{c}0.839 \\
(0.981)\end{array}$ & $\begin{array}{c}0.874 \\
(0.977)\end{array}$ & $\begin{array}{l}-4.106^{* *} \\
(1.967)\end{array}$ \\
\hline Country FE & no & no & yes & yes & yes & yes & - \\
\hline Year FE & yes & yes & yes & yes & yes & yes & yes \\
\hline $\mathrm{AR}(2)$ test & - & - & - & - & - & - & 0.281 \\
\hline Hansen test & - & - & - & - & - & - & 0.372 \\
\hline Countries & 58 & 58 & 58 & 58 & 58 & 58 & 58 \\
\hline Observations & 288 & 288 & 288 & 288 & 288 & 288 & 288 \\
\hline
\end{tabular}

Note: Standard errors in parenthesis. ***,**, and * indicate significance at the 1,5 , and 10 percent level, respectively. The standard errors in columns (1), (2), and (3) are clustered at the country level, while those from (4) to (6) are bootstrapped with 50 iterations. Column (7) uses
collapsed instruments and an orthogonal transformation. All of the variables are in logarithms, while population growth and robots growth were transformed with the zero-skewness $\log$ transformation. CorrFE refers to the corrected fixed effects with $b b$ indicating initialisation by the Blundell and Bond (1998) estimator, $a b$ initialisation by Arellano and Bond (1991) estimator, and $a h$ initialisation by the Anderson and Hsiao (1982) estimator. $\hat{p}_{t-1}$ is the growth rate of robot density (either manufacturing robots, or the total amount of robots per 1000 inhabitants) between periods $t-1$ and $t-2, n_{i, t-1}$ is the population growth rate between periods $t-1$ and $t-2, s_{i, t-1}$ is the gross investment rate in period $t-1$, and serv $_{t-1}$ stands for the contribution of the service sector to overall GDP in $t-1$. 
Table A.12: Total robots - capital stock as control

\begin{tabular}{|c|c|c|c|c|c|c|c|}
\hline & $\begin{array}{c}(1) \\
\text { POLS }\end{array}$ & $\begin{array}{l}(2) \\
R E\end{array}$ & $\begin{array}{l}(3) \\
\mathrm{FE}\end{array}$ & $\begin{array}{c}(4) \\
\text { corrFE (bb) }\end{array}$ & $\begin{array}{c}(5) \\
\text { corrFE }(a b)\end{array}$ & $\begin{array}{c}\text { (6) } \\
\text { corrFE (ah) }\end{array}$ & $\begin{array}{c}(7) \\
\text { GMM (sys) }\end{array}$ \\
\hline$\hat{p}_{t-1}$ & & & & $\begin{array}{c}0.322^{* * *} \\
(0.078)\end{array}$ & $\begin{array}{c}0.263^{* * *} \\
(0.092)\end{array}$ & $\begin{array}{c}0.248^{* * *} \\
(0.096)\end{array}$ & $\begin{array}{c}0.290^{*} \\
(0.172)\end{array}$ \\
\hline$n_{t-1}$ & $\begin{array}{c}-0.513 \\
(0.338)\end{array}$ & $\begin{array}{c}-0.665^{*} \\
(0.364)\end{array}$ & $\begin{array}{c}-1.877^{* *} \\
(0.814)\end{array}$ & $\begin{array}{c}-1.565^{* *} \\
(0.617)\end{array}$ & $\begin{array}{c}-1.669^{* * * *} \\
(0.592)\end{array}$ & $\begin{array}{c}-1.691^{* * *} \\
(0.596)\end{array}$ & $\begin{array}{l}-1.664 \\
(1.319)\end{array}$ \\
\hline$s_{t-1}$ & $\begin{array}{c}0.046 \\
(0.113)\end{array}$ & $\begin{array}{c}0.074 \\
(0.124)\end{array}$ & $\begin{array}{c}0.471 \\
(0.429)\end{array}$ & $\begin{array}{c}0.348 \\
(0.320)\end{array}$ & $\begin{array}{c}0.371 \\
(0.299)\end{array}$ & $\begin{array}{c}0.382 \\
(0.300)\end{array}$ & $\begin{array}{c}0.225 \\
(0.521)\end{array}$ \\
\hline capital stock ${ }_{t-1}$ & $\begin{array}{c}-0.022 \\
(0.048)\end{array}$ & $\begin{array}{l}-0.027 \\
(0.044)\end{array}$ & $\begin{array}{c}-0.518 \\
(0.547)\end{array}$ & $\begin{array}{l}-0.455 \\
(0.366)\end{array}$ & $\begin{array}{l}-0.450 \\
(0.338)\end{array}$ & $\begin{array}{l}-0.458 \\
(0.337)\end{array}$ & $\begin{array}{c}-0.189 \\
(0.184)\end{array}$ \\
\hline Country FE & no & no & yes & yes & yes & yes & - \\
\hline Year Dummies & yes & yes & yes & yes & yes & yes & yes \\
\hline $\mathrm{AR}(2)$ test & - & - & - & - & - & - & 0.345 \\
\hline Hansen test & - & - & - & - & - & - & 0.090 \\
\hline Number of Countries & 59 & 59 & 59 & 59 & 59 & 59 & 59 \\
\hline Observations & 295 & 295 & 295 & 295 & 295 & 295 & 295 \\
\hline
\end{tabular}

Table A.13: Manufacturing robots - capital stock as control

\begin{tabular}{|c|c|c|c|c|c|c|c|}
\hline & $\begin{array}{c}(1) \\
\text { POLS }\end{array}$ & $\begin{array}{l}(2) \\
R E\end{array}$ & $\begin{array}{l}(3) \\
\mathrm{FE}\end{array}$ & $\begin{array}{c}(4) \\
\text { corrFE (bb) }\end{array}$ & $\begin{array}{c}(5) \\
\text { corrFE (ab) }\end{array}$ & $\begin{array}{c}(6) \\
\text { corrFE (ah) }\end{array}$ & $\begin{array}{c}(7) \\
\text { GMM (sys) }\end{array}$ \\
\hline$\hat{p}_{t-1}$ & & & & $\begin{array}{c}0.361^{* * *} \\
(0.079)\end{array}$ & $\begin{array}{c}0.340^{* * *} \\
(0.086)\end{array}$ & $\begin{array}{c}0.316 * * * \\
(0.094)\end{array}$ & $\begin{array}{c}0.047 \\
(0.108)\end{array}$ \\
\hline$n_{t-1}$ & $\begin{array}{l}-0.501 \\
(0.338)\end{array}$ & $\begin{array}{c}-0.640^{*} \\
(0.360)\end{array}$ & $\begin{array}{c}-2.211^{* *} \\
(0.931)\end{array}$ & $\begin{array}{c}-1.669^{* * *} \\
(0.639)\end{array}$ & $\begin{array}{c}-1.715^{* * *} \\
(0.631)\end{array}$ & $\begin{array}{c}-1.772^{* * *} \\
(0.637)\end{array}$ & $\begin{array}{c}-5.383^{* * *} \\
(1.255)\end{array}$ \\
\hline$s_{t-1}$ & $\begin{array}{c}0.011 \\
(0.084)\end{array}$ & $\begin{array}{c}0.026 \\
(0.091)\end{array}$ & $\begin{array}{c}0.241 \\
(0.415)\end{array}$ & $\begin{array}{c}0.074 \\
(0.323)\end{array}$ & $\begin{array}{c}0.089 \\
(0.310)\end{array}$ & $\begin{array}{c}0.102 \\
(0.310)\end{array}$ & $\begin{array}{c}0.452 \\
(0.590)\end{array}$ \\
\hline capital stock $_{t-1}$ & $\begin{array}{c}0.003 \\
(0.049)\end{array}$ & $\begin{array}{c}0.000 \\
(0.047)\end{array}$ & $\begin{array}{l}-0.416 \\
(0.541)\end{array}$ & $\begin{array}{l}-0.429 \\
(0.371)\end{array}$ & $\begin{array}{c}-0.401 \\
(0.352)\end{array}$ & $\begin{array}{l}-0.411 \\
(0.352)\end{array}$ & $\begin{array}{l}-0.404 \\
(0.246)\end{array}$ \\
\hline Country FE & no & no & yes & yes & yes & yes & - \\
\hline Year Dummies & yes & yes & yes & yes & yes & yes & yes \\
\hline $\mathrm{AR}(2)$ test & - & - & - & - & - & - & 0.255 \\
\hline Hansen test & - & - & - & - & - & - & 0.774 \\
\hline Number of Countries & 59 & 59 & 59 & 59 & 59 & 59 & 59 \\
\hline Observations & 295 & 295 & 295 & 295 & 295 & 295 & 295 \\
\hline
\end{tabular}

Table A.14: Total robots - gross fixed capital formation (as a fraction of GDP) as control

\begin{tabular}{|c|c|c|c|c|c|c|c|}
\hline & $\begin{array}{l}(1) \\
\text { POLS }\end{array}$ & $\begin{array}{l}(2) \\
R E\end{array}$ & $\begin{array}{l}(3) \\
\mathrm{FE}\end{array}$ & $\begin{array}{c}(4) \\
\text { corrFE (bb) }\end{array}$ & $\begin{array}{c}\text { (5) } \\
\text { corrFE }(a b)\end{array}$ & $\begin{array}{c}\text { (6) } \\
\text { corrFE (ah) }\end{array}$ & $\begin{array}{c}(7) \\
\text { GMM (sys) }\end{array}$ \\
\hline$\hat{p}_{t-1}$ & & & & $\begin{array}{c}0.312^{* * *} \\
(0.072)\end{array}$ & $\begin{array}{c}0.262^{* * *} \\
(0.092)\end{array}$ & $\begin{array}{l}0.247^{* *} \\
(0.097)\end{array}$ & $\begin{array}{c}0.109 \\
(0.134)\end{array}$ \\
\hline$n_{t-1}$ & $\begin{array}{l}-0.430 \\
(0.342)\end{array}$ & $\begin{array}{l}-0.586 \\
(0.370)\end{array}$ & $\begin{array}{c}-2.006^{* *} \\
(0.884)\end{array}$ & $\begin{array}{c}-1.667^{* *} \\
(0.775)\end{array}$ & $\begin{array}{c}-1.761^{* *} \\
(0.752)\end{array}$ & $\begin{array}{c}-1.787^{* *} \\
(0.757)\end{array}$ & $\begin{array}{c}-2.743^{* *} \\
(1.249)\end{array}$ \\
\hline$s_{t-1}$ & $\begin{array}{l}-0.006 \\
(0.088)\end{array}$ & $\begin{array}{c}0.013 \\
(0.099)\end{array}$ & $\begin{array}{c}0.247 \\
(0.849)\end{array}$ & $\begin{array}{c}0.077 \\
(0.577)\end{array}$ & $\begin{array}{c}0.115 \\
(0.532)\end{array}$ & $\begin{array}{c}0.132 \\
(0.532)\end{array}$ & $\begin{array}{l}-0.527 \\
(0.918)\end{array}$ \\
\hline capital formation $_{t-1}$ & $\begin{array}{l}0.678^{* *} \\
(0.311)\end{array}$ & $\begin{array}{l}0.579^{*} \\
(0.311)\end{array}$ & $\begin{array}{c}0.267 \\
(0.726)\end{array}$ & $\begin{array}{c}0.342 \\
(0.678)\end{array}$ & $\begin{array}{c}0.323 \\
(0.640)\end{array}$ & $\begin{array}{c}0.313 \\
(0.637)\end{array}$ & $\begin{array}{c}1.385 \\
(1.322)\end{array}$ \\
\hline Country FE & no & no & yes & yes & yes & yes & - \\
\hline Year Dummies & yes & yes & yes & yes & yes & yes & yes \\
\hline $\mathrm{AR}(2)$ test & - & - & - & - & - & - & 0.311 \\
\hline Hansen test & - & - & - & - & - & - & 0.973 \\
\hline Number of Countries & 60 & 60 & 60 & 60 & 60 & 60 & 60 \\
\hline Observations & 300 & 300 & 300 & 300 & 300 & 300 & 300 \\
\hline
\end{tabular}

Note: Standard errors in parenthesis. $* * * * * *$, and * indicate significance at the 1,5 , and 10 percent level, respectively. The standard errors in columns (1), (2), and (3) are clustered at the country level, while those from (4) to (6) are bootstrapped with 50 iterations. Column (7) uses
collapsed instruments and an orthogonal transformation. All of the variables are in logarithms, while population growth and robots growth were transformed with the zero-skewness log transformation. CorrFE refers to the corrected fixed effects with $b b$ indicating initialisation by the were transformed with the zero-skewness log transformation. CorrFE refers to the corrected fixed effects with $b b$ indicating initialisation by the
Blundell and Bond (1998) estimator, $a b$ initialisation by Arellano and Bond (1991) estimator, and $a h$ initialisation by the Anderson and Hsia (1982) estimator. $\hat{p}_{t-1}$ is the growth rate of robot density (either manufacturing robots, or the total amount of robots per 1000 inhabitants) between periods $t-1$ and $t-2, n_{i, t-1}$ is the population growth rate between periods $t-1$ and $t-2, s_{i, t-1}$ is the gross investment rate in period $t-1$, and capital formation $t-1$ stands for the gross fixed capital formation in $t-1$. 
Table A.15: Manufacturing robots - gross fixed capital formation (as a fraction of GDP) as control

\begin{tabular}{|c|c|c|c|c|c|c|c|}
\hline & $\begin{array}{c}(1) \\
\text { POLS }\end{array}$ & $\begin{array}{l}(2) \\
\mathrm{RE}\end{array}$ & $\begin{array}{l}(3) \\
\mathrm{FE}\end{array}$ & $\begin{array}{c}(4) \\
\text { corrFE (bb) }\end{array}$ & $\begin{array}{c}(5) \\
\text { corrFE (ab) }\end{array}$ & $\begin{array}{c}(6) \\
\text { corrFE (ah) }\end{array}$ & $\begin{array}{c}(7) \\
\text { GMM (sys) }\end{array}$ \\
\hline$\hat{p}_{t-1}$ & & & & $\begin{array}{c}0.351^{* * *} \\
(0.068)\end{array}$ & $\begin{array}{c}0.335^{* * * *} \\
(0.078)\end{array}$ & $\begin{array}{c}0.312^{* * *} \\
(0.084)\end{array}$ & $\begin{array}{c}0.154 \\
(0.110)\end{array}$ \\
\hline$n_{t-1}$ & $\begin{array}{c}-0.410 \\
(0.329)\end{array}$ & $\begin{array}{c}-0.547 \\
(0.357)\end{array}$ & $\begin{array}{c}-2.301^{* *} \\
(0.977)\end{array}$ & $\begin{array}{c}-1.754^{* *} \\
(0.783)\end{array}$ & $\begin{array}{c}-1.782^{* *} \\
(0.773)\end{array}$ & $\begin{array}{c}-1.842^{* *} \\
(0.780)\end{array}$ & $\begin{array}{c}-2.907^{* *} \\
(1.356)\end{array}$ \\
\hline$s_{t-1}$ & $\begin{array}{c}-0.036 \\
(0.054)\end{array}$ & $\begin{array}{c}-0.026 \\
(0.060)\end{array}$ & $\begin{array}{l}-0.113 \\
(0.779)\end{array}$ & $\begin{array}{c}-0.342 \\
(0.580)\end{array}$ & $\begin{array}{l}-0.306 \\
(0.551)\end{array}$ & $\begin{array}{c}-0.293 \\
(0.548)\end{array}$ & $\begin{array}{l}-0.338 \\
(0.695)\end{array}$ \\
\hline capital formation $_{t-1}$ & $\begin{array}{l}0.682^{* *} \\
(0.297)\end{array}$ & $\begin{array}{l}0.596^{* *} \\
(0.292)\end{array}$ & $\begin{array}{c}0.495 \\
(0.641)\end{array}$ & $\begin{array}{c}0.576 \\
(0.687)\end{array}$ & $\begin{array}{c}0.553 \\
(0.664)\end{array}$ & $\begin{array}{c}0.553 \\
(0.659)\end{array}$ & $\begin{array}{c}1.460 \\
(1.210)\end{array}$ \\
\hline Country FE & no & no & yes & yes & yes & yes & - \\
\hline Year Dummies & yes & yes & yes & yes & yes & yes & yes \\
\hline $\mathrm{AR}(2)$ test & - & - & - & - & - & - & 0.677 \\
\hline Hansen test & - & - & - & - & - & - & 0.419 \\
\hline Number of Countries & 60 & 60 & 60 & 60 & 60 & 60 & 60 \\
\hline Observations & 300 & 300 & 300 & 300 & 300 & 300 & 300 \\
\hline
\end{tabular}

Table A.16: Total robots - life expectancy, dependency ratio and exports of robots as extra controls

\begin{tabular}{|c|c|c|c|c|c|c|c|}
\hline & $\begin{array}{c}(1) \\
\text { POLS }\end{array}$ & $\begin{array}{l}(2) \\
\text { RE }\end{array}$ & $\begin{array}{l}(3) \\
\mathrm{FE}\end{array}$ & $\begin{array}{c}(4) \\
\text { corrFE (bb) }\end{array}$ & $\begin{array}{c}(5) \\
\text { corrFE (ab) }\end{array}$ & $\begin{array}{c}(6) \\
\text { corrFE (ah) }\end{array}$ & $\begin{array}{c}(7) \\
\text { GMM (sys) }\end{array}$ \\
\hline$\hat{p}_{t-1}$ & & & & $\begin{array}{c}0.169^{* *} \\
(0.078)\end{array}$ & $\begin{array}{c}0.095 \\
(0.087)\end{array}$ & $\begin{array}{c}0.092 \\
(0.087)\end{array}$ & $\begin{array}{c}0.025 \\
(0.144)\end{array}$ \\
\hline$n_{t-1}$ & $\begin{array}{l}-0.731 \\
(0.515)\end{array}$ & $\begin{array}{c}-0.986^{* *} \\
(0.477)\end{array}$ & $\begin{array}{l}-2.105^{*} \\
(1.206)\end{array}$ & $\begin{array}{c}-1.614^{*} \\
(0.901)\end{array}$ & $\begin{array}{c}-1.899^{* * *} \\
(0.897)\end{array}$ & $\begin{array}{c}-1.913^{* *} \\
(0.923)\end{array}$ & $\begin{array}{c}-2.363 \\
(1.810)\end{array}$ \\
\hline$s_{t-1}$ & $\begin{array}{c}0.122 \\
(0.177)\end{array}$ & $\begin{array}{c}0.138 \\
(0.192)\end{array}$ & $\begin{array}{c}0.440 \\
(0.750)\end{array}$ & $\begin{array}{c}0.506 \\
(0.575)\end{array}$ & $\begin{array}{c}0.529 \\
(0.550)\end{array}$ & $\begin{array}{c}0.530 \\
(0.550)\end{array}$ & $\begin{array}{l}-1.183 \\
(1.598)\end{array}$ \\
\hline Dependency & $\begin{array}{l}-0.097 \\
(0.364)\end{array}$ & $\begin{array}{c}-0.164 \\
(0.321)\end{array}$ & $\begin{array}{c}0.116 \\
(1.516)\end{array}$ & $\begin{array}{c}0.342 \\
(1.968)\end{array}$ & $\begin{array}{c}0.170 \\
(1.827)\end{array}$ & $\begin{array}{c}0.144 \\
(1.833)\end{array}$ & $\begin{array}{c}-1.186 \\
(1.519)\end{array}$ \\
\hline Life Exp. & $\begin{array}{c}-2.571 \\
(1.798)\end{array}$ & $\begin{array}{l}-2.023 \\
(1.608)\end{array}$ & $\begin{array}{c}4.791 \\
(9.615)\end{array}$ & $\begin{array}{l}2.255 \\
(9.025)\end{array}$ & $\begin{array}{l}3.005 \\
(8.550)\end{array}$ & $\begin{array}{l}3.058 \\
(8.493)\end{array}$ & $\begin{array}{c}-1.620 \\
(16.852)\end{array}$ \\
\hline Robo. Expo. & $\begin{array}{c}0.025 \\
(0.047)\end{array}$ & $\begin{array}{c}0.002 \\
(0.042)\end{array}$ & $\begin{array}{l}-0.101 \\
(0.100)\end{array}$ & $\begin{array}{l}-0.105 \\
(0.100)\end{array}$ & $\begin{array}{l}-0.112 \\
(0.097)\end{array}$ & $\begin{array}{l}-0.112 \\
(0.098)\end{array}$ & $\begin{array}{l}-0.286 \\
(0.194)\end{array}$ \\
\hline Country FE & no & no & yes & yes & yes & yes & yes \\
\hline Time FE & yes & yes & yes & yes & yes & yes & yes \\
\hline $\mathrm{AR}(2)$ test & - & - & - & - & - & - & 0.521 \\
\hline Hansen Test & - & - & - & - & - & - & 0.531 \\
\hline Countries & 60 & 60 & 60 & 60 & 60 & 60 & 60 \\
\hline Observations & 240 & 240 & 240 & 240 & 240 & 240 & 240 \\
\hline
\end{tabular}

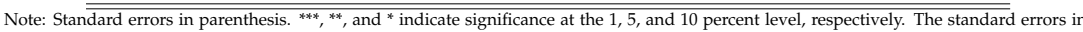
columns (1), (2), and (3) are clustered at the country level, while those from (4) to (6) are bootstrapped with 50 iterations. Column (7) uses collapsed instruments and an orthogonal transformation. All of the variables are in logarithms, while population growth and robots growth were transformed with the zero-skewness log transformation. CorrFE refers to the corrected fixed effects with $b b$ indicating initialisation by the Blundell and Bond (1998) estimator, ab initialisation by Arellano and Bond (1991) estimator, and ah initialisation by the Anderson and Hsiao (1982) estimator. $\hat{p}_{t-1}$ is the growth rate of robot density (either manufacturing robots, or the total amount of robots per 1000 inhabitants) period $t-1$, dependency $y_{t-1}$ stands for the dependency ratio in $t-1$, life exp. $t-1$ for life expectancy in $t-1$ and robo. expo $\cdot t-1$ for the exports of industrial robots in $t-1$.

Table A.17: Manufacturing robots - life expectancy, dependency ratio and exports of robots as extra controls

\begin{tabular}{|c|c|c|c|c|c|c|c|}
\hline & $\begin{array}{l}(1) \\
\text { POLS }\end{array}$ & $\begin{array}{l}(2) \\
R E\end{array}$ & $\begin{array}{l}(3) \\
\mathrm{FE}\end{array}$ & $\begin{array}{c}(4) \\
\text { corrFE (bb) }\end{array}$ & $\begin{array}{c}(5) \\
\text { corrFE }(a b)\end{array}$ & $\begin{array}{c}\text { (6) } \\
\text { corrFE (ah) }\end{array}$ & $\begin{array}{c}(7) \\
\text { GMM (sys) }\end{array}$ \\
\hline$\hat{p}_{t-1}$ & & & $0.134^{*}$ & $\begin{array}{c}0.049 \\
(0.074)\end{array}$ & $\begin{array}{c}0.043 \\
(0.082)\end{array}$ & $\begin{array}{l}-0.061 \\
(0.082)\end{array}$ & (0.111) \\
\hline$n_{t-1}$ & $\begin{array}{l}-0.622 \\
(0.509)\end{array}$ & $\begin{array}{c}-0.976^{* *} \\
(0.477)\end{array}$ & $\begin{array}{l}-2.577^{*} \\
(1.288)\end{array}$ & $\begin{array}{c}-2.178^{* *} \\
(0.921)\end{array}$ & $\begin{array}{c}-2.463^{* * *} \\
(0.904)\end{array}$ & $\begin{array}{c}-2.481^{* * *} \\
(0.910)\end{array}$ & $\begin{array}{l}-2.095 \\
(2.138)\end{array}$ \\
\hline$s_{t-1}$ & $\begin{array}{c}0.081 \\
(0.138)\end{array}$ & $\begin{array}{c}0.086 \\
(0.143)\end{array}$ & $\begin{array}{c}0.244 \\
(0.754)\end{array}$ & $\begin{array}{c}0.360 \\
(0.590)\end{array}$ & $\begin{array}{c}0.374 \\
(0.557)\end{array}$ & $\begin{array}{c}0.375 \\
(0.554)\end{array}$ & $\begin{array}{c}-0.843 \\
(1.599)\end{array}$ \\
\hline Dependency & $\begin{array}{l}-0.104 \\
(0.373)\end{array}$ & $\begin{array}{l}-0.247 \\
(0.326)\end{array}$ & $\begin{array}{c}-0.499 \\
(1.382)\end{array}$ & $\begin{array}{l}-0.334 \\
(2.017)\end{array}$ & $\begin{array}{l}-0.458 \\
(1.847)\end{array}$ & $\begin{array}{l}-0.488 \\
(1.842)\end{array}$ & $\begin{array}{l}-1.079 \\
(1.667)\end{array}$ \\
\hline Life Exp. & $\begin{array}{l}-2.886 \\
(1.842)\end{array}$ & $\begin{array}{l}-2.255 \\
(1.607)\end{array}$ & $\begin{array}{c}8.150 \\
(9.383)\end{array}$ & $\begin{array}{l}5.841 \\
(9.282)\end{array}$ & $\begin{array}{c}6.805 \\
(8.698)\end{array}$ & $\begin{array}{c}6.914 \\
(8.579)\end{array}$ & $\begin{array}{c}-4.852 \\
(15.850)\end{array}$ \\
\hline Robo. Expo. & $\begin{array}{c}0.044 \\
(0.048)\end{array}$ & $\begin{array}{c}0.038 \\
(0.045)\end{array}$ & $\begin{array}{c}0.028 \\
(0.111)\end{array}$ & $\begin{array}{c}0.017 \\
(0.102)\end{array}$ & $\begin{array}{c}0.015 \\
(0.098)\end{array}$ & $\begin{array}{c}0.015 \\
(0.099)\end{array}$ & $\begin{array}{c}-0.098 \\
(0.191)\end{array}$ \\
\hline Country FE & no & no & yes & yes & yes & yes & yes \\
\hline Time FE & yes & yes & yes & yes & yes & yes & yes \\
\hline $\mathrm{AR}(2)$ test & - & - & - & - & - & - & 0.979 \\
\hline Hansen Test & - & - & - & - & - & - & 0.799 \\
\hline Countries & 60 & 60 & 60 & 60 & 60 & 60 & 60 \\
\hline Observations & 240 & 240 & 240 & 240 & 240 & 240 & 240 \\
\hline
\end{tabular}

Note: Standard errors in parenthesis. ${ }^{* * *}$, **, and ${ }^{*}$ indicate significance at the 1,5 , and 10 percent level, respectively. The standard errors in columns (1), (2), and (3) are clustered at the country level, while those from (4) to (6) are bootstrapped with 50 iterations. Column (7) uses collapsed instruments and an orthogonal transformation. All of the variables are in logarithms, while population growth and robots growth Blundell and Bond (1998) estimator, $a b$ initialisation by Arellano and Bond (1991) estimator, and $a h$ initialisation by the Anderson and Hsiao (1982) estimator. "Dependency" stands for the dependency ratio, "life exp." for life expectancy and "robo. expo." for the exports of industrial robots. $\hat{p}_{t-1}$ is the growth rate of robot density (either manufacturing robots, or the total amount of robots per 1000 inhabitants) between periods $t-1$ and $t-2, n_{i, t-1}$ is the population growth rate between periods $t-1$ and $t-2, s_{i, t-1}$ is the gross investment rate in period $t-1$, dependency $y_{t-1}$ stands for the dependency ratio in $t-1$, life exp.t-1 for life expectancy in $t-1$ and robo. expo. $t-1$ for the exports of 
As further robustness checks, we used two-year averages instead of averaging the data over three years. Tables A.18 and A.19 show the corresponding results. As before, we observe a statistically significant negative correlation between the population growth rate and the growth of robot density (either of the total stock of robots or those employed in the manufacturing sector). However, the magnitude of the correlation is smaller in absolute value. The investment rate coefficient continues to be statistically insignificant in both tables, having a positive sign in most of the cases. Only column (7) from Table A.19 displays a negative investment rate coefficient, although this estimate should be taken with caution because the AR(2) test cannot rule out remaining autocorrelation of the residuals at the 10 percent significance level. Moreover, we also constructed two alternative robot stocks using 5 percent and 15 percentas alternative depreciation rates. The estimates for the baseline model are shown in Tables A.20 and A.22 (for the total stock of robots) and Tables A.21 and A.23 (for manufacturing robots). We find no substantial differences from our previous estimates.

Table A.18: Total robots - 2-year averages instead of 3-year averages

\begin{tabular}{|c|c|c|c|c|c|c|c|}
\hline & $\begin{array}{c}(1) \\
\text { POLS }\end{array}$ & $\begin{array}{l}(2) \\
R E \\
\end{array}$ & $\begin{array}{l}(3) \\
\mathrm{FE}\end{array}$ & $\begin{array}{c}(4) \\
\text { corrFE (bb) }\end{array}$ & $\begin{array}{c}(5) \\
\text { corrFE }(a b)\end{array}$ & $\begin{array}{c}(6) \\
\text { corrFE (ah) }\end{array}$ & $\begin{array}{c}(7) \\
\text { GMM (sys) }\end{array}$ \\
\hline$\hat{p}_{t-1}$ & & & & $\begin{array}{c}0.366^{* * *} \\
(0.049)\end{array}$ & $\begin{array}{c}0.351^{* * *} \\
(0.050)\end{array}$ & $\begin{array}{c}0.393^{* * *} \\
(0.051)\end{array}$ & $\begin{array}{c}0.291 * * * \\
(0.071)\end{array}$ \\
\hline$n_{t-1}$ & $\begin{array}{l}-0.435 \\
(0.294)\end{array}$ & $\begin{array}{l}-0.606^{*} \\
(0.344)\end{array}$ & $\begin{array}{l}-1.160^{*} \\
(0.594)\end{array}$ & $\begin{array}{c}-0.717^{* *} \\
(0.359)\end{array}$ & $\begin{array}{c}-0.736^{* *} \\
(0.343)\end{array}$ & $\begin{array}{l}-0.706^{*} \\
(0.370)\end{array}$ & $\begin{array}{l}-1.415^{*} \\
(0.760)\end{array}$ \\
\hline$s_{t-1}$ & $\begin{array}{c}0.093 \\
(0.099)\end{array}$ & $\begin{array}{c}0.135 \\
(0.108)\end{array}$ & $\begin{array}{c}0.380 \\
(0.326)\end{array}$ & $\begin{array}{c}0.230 \\
(0.214)\end{array}$ & $\begin{array}{c}0.247 \\
(0.196)\end{array}$ & $\begin{array}{c}0.257 \\
(0.208)\end{array}$ & $\begin{array}{c}0.091 \\
(0.155)\end{array}$ \\
\hline Country FE & no & no & yes & yes & yes & yes & - \\
\hline Year FE & yes & yes & yes & yes & yes & yes & yes \\
\hline $\mathrm{AR}(2)$ test & - & - & - & - & - & - & 0.143 \\
\hline Hansen test & - & - & - & - & - & - & 0.276 \\
\hline Countries & 60 & 60 & 60 & 60 & 60 & 60 & 60 \\
\hline Observations & 539 & 539 & 539 & 539 & 539 & 539 & 539 \\
\hline
\end{tabular}

Table A.19: Manufacturing robots - 2-year averages instead of 3-year averages

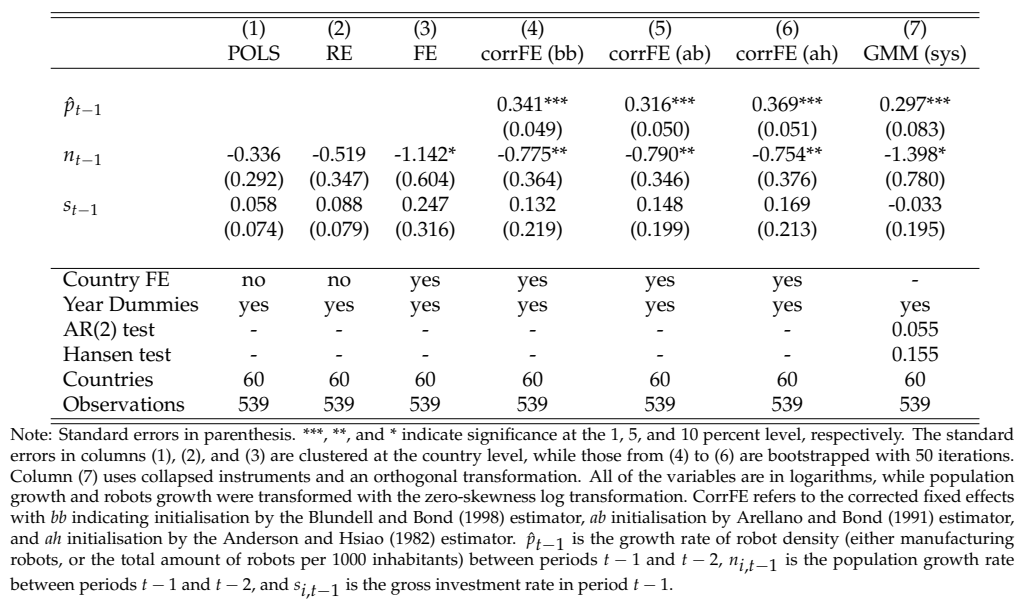


Table A.20: Total robots - 5\% depreciation rate

\begin{tabular}{|c|c|c|c|c|c|c|c|}
\hline & $\begin{array}{c}1) \\
\text { POLS }\end{array}$ & $\begin{array}{l}\text { (2) } \\
\text { RE }\end{array}$ & $\begin{array}{l}(3) \\
\text { FE }\end{array}$ & $\begin{array}{c}(4) \\
\text { corrFE (bb) }\end{array}$ & $\begin{array}{c}(5) \\
\text { corrFE }(a b)\end{array}$ & $\begin{array}{c}(6) \\
\text { corrFE (ah) }\end{array}$ & $\begin{array}{c}(7) \\
\text { GMM (sys) }\end{array}$ \\
\hline$\hat{p}_{t-1}$ & & & & $\begin{array}{c}0.339^{* * *} \\
(0.077)\end{array}$ & $\begin{array}{c}0.294^{* * *} \\
(0.088)\end{array}$ & $\begin{array}{c}0.280^{* * *} \\
(0.099)\end{array}$ & $\begin{array}{l}0.299^{* *} \\
(0.137)\end{array}$ \\
\hline$n_{t-1}$ & $\begin{array}{l}-0.591^{*} \\
(0.332)\end{array}$ & $\begin{array}{c}-0.718^{* *} \\
(0.353)\end{array}$ & $\begin{array}{c}-2.151^{* *} \\
(0.937)\end{array}$ & $\begin{array}{c}-1.731^{* * *} \\
(0.645)\end{array}$ & $\begin{array}{c}-1.835^{* * *} \\
(0.612)\end{array}$ & $\begin{array}{c}-1.862^{* * *} \\
(0.608)\end{array}$ & $\begin{array}{c}-2.687^{* *} \\
(1.291)\end{array}$ \\
\hline$s_{t-1}$ & $\begin{array}{c}0.077 \\
(0.125)\end{array}$ & $\begin{array}{c}0.103 \\
(0.136)\end{array}$ & $\begin{array}{c}0.545 \\
(0.519)\end{array}$ & $\begin{array}{c}0.385 \\
(0.387)\end{array}$ & $\begin{array}{c}0.405 \\
(0.371)\end{array}$ & $\begin{array}{c}0.419 \\
(0.374)\end{array}$ & $\begin{array}{l}-0.146 \\
(0.622)\end{array}$ \\
\hline Country FE & no & no & yes & yes & yes & yes & - \\
\hline Year FE & yes & yes & yes & yes & yes & yes & yes \\
\hline $\mathrm{AR}(2)$ test & - & - & - & - & - & - & 0.783 \\
\hline Hansen test & - & - & - & - & - & - & 0.177 \\
\hline Countries & 60 & 60 & 60 & 60 & 60 & 60 & 60 \\
\hline Observations & 300 & 300 & 300 & 300 & 300 & 300 & 300 \\
\hline
\end{tabular}

Note: $\overline{\overline{S t a n d a r d} \text { errors in parenthesis. }{ }^{* * *} \text {, **, and }{ }^{*} \text { indicate significance at the } 1,5 \text {, and } 10 \text { percent level, respectively. The standard errors in columns }}$ (1), (2), and (3) are clustered at the country level, while those from (4) to (6) are bootstrapped with 50 iterations. Column (7) uses collapsed instruments and an orthogonal transformation. All of the variables are in logarithms, while population growth and robots growth were transformed with the zero-skewness by Arellon and Bond (1991) estimor, and ah initialisation by the Anderson and Hino (1982) estimator $\hat{p}_{t}-1$ is the growth rate of robot density (either manufacturing robots, or the total amount of robots per 1000 inhabitants) between periods $t-1$ and $t-2, n_{i, t}$ is the population growth rate between periods $t-1$ and $t-2$, and $s_{i, t-1}$ is the gross investment rate in period $t-1$.

Table A.21: Manufacturing robots 5\% depreciation rate

\begin{tabular}{|c|c|c|c|c|c|c|c|}
\hline & $\begin{array}{c}(1) \\
\text { POLS }\end{array}$ & $\begin{array}{l}(2) \\
\text { RE }\end{array}$ & $\begin{array}{l}(3) \\
\text { FE }\end{array}$ & $\begin{array}{c}(4) \\
\text { corrFE (bb) }\end{array}$ & $\begin{array}{c}(5) \\
\text { corrFE (ab) }\end{array}$ & $\begin{array}{c}(6) \\
\text { corrFE (ah) }\end{array}$ & $\begin{array}{c}(7) \\
\text { GMM (sys) }\end{array}$ \\
\hline$\hat{p}_{t-1}$ & & & & $\begin{array}{c}0.300^{* * *} \\
(0.076)\end{array}$ & $\begin{array}{c}0.246^{* * *} \\
(0.085)\end{array}$ & $\begin{array}{l}0.227^{* *} \\
(0.093)\end{array}$ & $\begin{array}{c}0.200 \\
(0.128)\end{array}$ \\
\hline$n_{t-1}$ & $\begin{array}{c}-0.526 \\
(0.345)\end{array}$ & $\begin{array}{c}-0.673^{*} \\
(0.370)\end{array}$ & $\begin{array}{c}-2.332^{* *} \\
(1.018)\end{array}$ & $\begin{array}{c}-2.018^{* * *} \\
(0.662)\end{array}$ & $\begin{array}{c}-2.116^{* * *} \\
(0.623)\end{array}$ & $\begin{array}{c}-2.147^{* * *} \\
(0.618)\end{array}$ & $\begin{array}{c}-3.024^{* * *} \\
(1.117)\end{array}$ \\
\hline$s_{t-1}$ & $\begin{array}{c}0.051 \\
(0.111)\end{array}$ & $\begin{array}{c}0.070 \\
(0.117)\end{array}$ & $\begin{array}{c}0.318 \\
(0.517)\end{array}$ & $\begin{array}{c}0.229 \\
(0.395)\end{array}$ & $\begin{array}{c}0.244 \\
(0.376)\end{array}$ & $\begin{array}{c}0.258 \\
(0.376)\end{array}$ & $\begin{array}{c}0.094 \\
(0.458)\end{array}$ \\
\hline Country FE & no & no & yes & yes & yes & yes & - \\
\hline Year FE & yes & yes & yes & yes & yes & yes & yes \\
\hline $\mathrm{AR}(2)$ test & - & - & - & - & - & - & 0.884 \\
\hline Hansen test & - & - & - & - & - & - & 0.119 \\
\hline Countries & 60 & 60 & 60 & 60 & 60 & 60 & 60 \\
\hline Observations & 300 & 300 & 300 & 300 & 300 & 300 & 300 \\
\hline
\end{tabular}

Note: Standard errors in parenthesis. ${ }^{* * *}, * *$, and ${ }^{*}$ indicate significance at the 1,5 , and 10 percent level, respectively. The standard errors in columns $(1)$, (2), and (3) are clustered at the country level, while those from (4) to (6) are bootstrapped with 50 iterations. Column (7) uses collapsed instruments and an orthogonal transformation. All of the variables are in logarithms, while population growth and robots growth were transformed with the zero-skewnes $\log$ transformation. CorrFE refers to the corrected fixed effects with $b b$ indicating initialisation by the Blundell and Bond (1998) estimator, $a b$ initialisation by Arellano and Bond (1991) estimator, and ah initialisation by the Anderson and Hsiao (1982) estimator. $\hat{p}_{t-1}$ is the growth rate of robot density (eithe periods $t-1$ and $t-2$, and $s_{i, t-1}$ is the gross investment rate in period $t-1$.

Table A.22: Total robots - 15\% depreciation rate

\begin{tabular}{|c|c|c|c|c|c|c|c|}
\hline & $\begin{array}{c}(1) \\
\text { POLS }\end{array}$ & $\begin{array}{l}\text { (2) } \\
\mathrm{RE}\end{array}$ & $\begin{array}{l}\text { (3) } \\
\text { FE }\end{array}$ & $\begin{array}{c}(4) \\
\text { corrFE (bb) }\end{array}$ & $\begin{array}{c}(5) \\
\text { corrFE }(a b)\end{array}$ & $\begin{array}{c}\text { (6) } \\
\text { corrFE (ah) }\end{array}$ & $\begin{array}{c}\text { (7) } \\
\text { GMM (sys) }\end{array}$ \\
\hline$\hat{p}_{t-1}$ & & & & $\begin{array}{c}0.301^{* * *} \\
(0.079)\end{array}$ & $\begin{array}{c}0.240^{* * *} \\
(0.092)\end{array}$ & $\begin{array}{l}0.227^{* *} \\
(0.098)\end{array}$ & $\begin{array}{c}0.174 \\
(0.106)\end{array}$ \\
\hline$n_{t-1}$ & $\begin{array}{l}-0.515 \\
(0.323)\end{array}$ & $\begin{array}{l}-0.683^{*} \\
(0.353)\end{array}$ & $\begin{array}{c}-1.945^{* *} \\
(0.858)\end{array}$ & $\begin{array}{c}-1.658^{* * *} \\
(0.562)\end{array}$ & $\begin{array}{c}-1.763^{* * *} \\
(0.528)\end{array}$ & $\begin{array}{c}-1.782^{* * *} \\
(0.523)\end{array}$ & $\begin{array}{c}-4.050^{* * *} \\
(1.377)\end{array}$ \\
\hline$s_{t-1}$ & $\begin{array}{c}0.055 \\
(0.118)\end{array}$ & $\begin{array}{c}0.081 \\
(0.126)\end{array}$ & $\begin{array}{c}0.337 \\
(0.477)\end{array}$ & $\begin{array}{c}0.247 \\
(0.335)\end{array}$ & $\begin{array}{c}0.266 \\
(0.319)\end{array}$ & $\begin{array}{c}0.272 \\
(0.319)\end{array}$ & $\begin{array}{c}0.291 \\
(0.542)\end{array}$ \\
\hline Country FE & no & no & yes & yes & yes & yes & - \\
\hline Year FE & yes & yes & yes & yes & yes & yes & yes \\
\hline $\mathrm{AR}(2)$ test & - & - & - & - & - & - & 0.790 \\
\hline Hansen test & - & - & - & - & - & - & 0.891 \\
\hline Countries & 60 & 60 & 60 & 60 & 60 & 60 & 60 \\
\hline Observations & 300 & 300 & 300 & 300 & 300 & 300 & 300 \\
\hline
\end{tabular}

Note: Standard errors in parenthesis. ${ }^{* * *}, * *$, and ${ }^{*}$ indicate significance at the 1,5, and 10 percent level, respectively. The standard errors in colum $n$ s (1), (2), and (3) are clustered at the country level, while those from (4) to (6) are bootstrapped with 50 iterations. Column (7) uses collapsed instruments and an orthogonal transformation. All of the variables are in logarithms, while population growth and robots growth were transformed with the zero-skewnes $\log$ transformation. CorrFE refers to the corrected fixed effects with $b b$ indicating initialisation by the Blundell and Bond (1998) estimator, $a b$ initialisation by Arellano and Bond (1991) estimator, and ah initialisation by the Anderson and Hsiao (1982) estimator. $\hat{p}_{t-1}$ is the growth rate of robot density (either manufacturing robots, or the total amount of robots per 1000 inhabitants) between periods $t-1$ and $t-2, n_{i, t-1}$ is the population growth rate between periods $t-1$ and $t-2$, and $s_{i, t-1}$ is the gross investment rate in period $t-1$. 
Table A.23: Manufacturing robots 15\% depreciation rate

\begin{tabular}{lccccccc}
\hline \hline & $(1)$ & $(2)$ & $(3)$ & $(4)$ & $(5)$ & $(6)$ & $(7)$ \\
& POLS & RE & FE & corrFE (bb) & corrFE (ab) & corrFE (ah) & GMM (sys) \\
\hline \multirow{2}{*}{$\hat{p}_{t-1}$} & & & & & & & \\
& & & & $0.233^{* * *}$ & $0.162^{*}$ & $0.149^{*}$ & 0.071 \\
$n_{t-1}$ & & & & $(0.078)$ & $(0.085)$ & $(0.090)$ & $(0.123)$ \\
& -0.419 & $-0.605^{*}$ & $-2.079^{* *}$ & $-1.901^{* * *}$ & $-1.998^{* * *}$ & $-2.012^{* * *}$ & $-4.411^{* * *}$ \\
$s_{t-1}$ & $(0.328)$ & $(0.365)$ & $(0.938)$ & $(0.575)$ & $(0.534)$ & $(0.531)$ & $(1.430)$ \\
& 0.009 & 0.022 & 0.072 & 0.059 & 0.071 & 0.075 & 0.290 \\
& $(0.086)$ & $(0.091)$ & $(0.469)$ & $(0.342)$ & $(0.321)$ & $(0.320)$ & $(0.491)$ \\
Country FE & no & no & yes & yes & yes & yes & - \\
Year FE & yes & yes & yes & yes & yes & yes & yes \\
AR(2) test & - & - & - & - & - & - & 0.481 \\
Hansen test & - & - & - & - & - & - & 0.813 \\
Countries & 60 & 60 & 60 & 60 & 60 & 60 & 60 \\
Observations & 300 & 300 & 300 & 300 & 300 & 300 & 300 \\
\hline
\end{tabular}

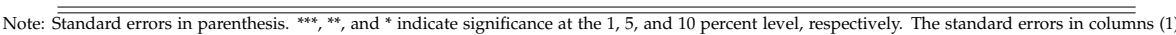
(2), and (3) are clustered at the country level, while those from (4) to (6) are bootstrapped with 50 iterations. Column (7) uses collapsed instruments and an orthogonal transformation. All of the variables are in logarithms, while population growth and robots growth were transformed with the zero-skewness $\log$ transformation. CorrFE refers to the corrected fixed effects with $b b$ indicating initialisation by the Blundell and Bond (1998) estimator, $a b$ initialisation by Arellano and Bond (1991) estimator, and ah initialisation by the Anderson and Hsiao (1982) estimator. $\hat{p}_{t-1}$ is the growth rate of robot density (either manufer periods $t-1$ and $t-2$, and $s_{i, t-1}$ is the gross investment rate in period $t-1$. 
In another sensitivity analysis, we exclude Germany, South Korea, the NAFTA countries, Japan, and China because these have the highest (manufacturing) robot density as well as very low fertility rates. Irrespective of this substantial reduction in the sample, the results are stable, as seen in Tables A.24 and A.25. We made a further change to the sample to include two extra available years (2014 and 2015 - although creating the last value as an average of two instead of three years). Furthermore, we replaced population growth with labour force growth. Tables A.26 and A.27 show the results based on including the two extra years for the total stock of robots. The point estimates are slightly smaller (in absolute value) but not statistically significantly different from each other. Tables A.28 and A.29 show the baseline estimates using labour force growth instead of population growth. As before, the results differ only slightly from the baseline estimates.

Table A.24: Total robots - reduced sample

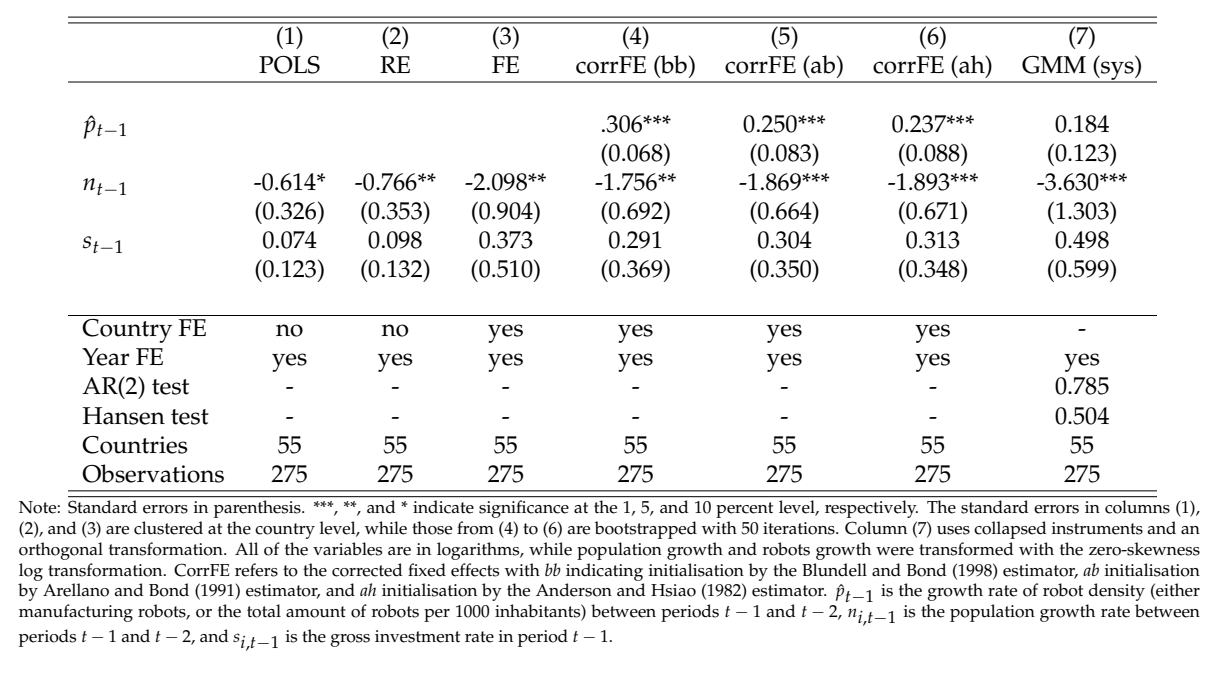

Table A.25: Manufacturing robots - reduced sample

\begin{tabular}{lccccccc}
\hline \hline & $(1)$ & $(2)$ & $(3)$ & $(4)$ & $(5)$ & $(6)$ & $(7)$ \\
& POLS & RE & FE & corrFE (bb) & corrFE (ab) & corrFE (ah) & GMM (sys) \\
\hline \multirow{2}{*}{$\hat{p}_{t-1}$} & & & & & & & \\
& & & & $0.247^{* * *}$ & $0.179^{* *}$ & $0.163^{*}$ & 0.076 \\
$n_{t-1}$ & -0.530 & $-0.704^{*}$ & $-2.264^{* *}$ & $-2.038^{* * *}$ & $-2.147^{* * *}$ & $-2.170^{* * *}$ & $-4.138^{* * *}$ \\
& $(0.336)$ & $(0.368)$ & $(0.983)$ & $(0.711)$ & $(0.674)$ & $(0.680)$ & $(1.164)$ \\
$s_{t-1}$ & 0.035 & 0.050 & 0.123 & 0.111 & 0.117 & 0.124 & 0.531 \\
& $(0.098)$ & $(0.103)$ & $(0.502)$ & $(0.376)$ & $(0.352)$ & $(0.351)$ & $(0.569)$ \\
& & & & & & & \\
Country FE & no & no & yes & yes & yes & yes & - \\
Year FE & yes & yes & yes & yes & yes & yes & yes \\
AR(2) test & - & - & - & - & - & - & 0.429 \\
Hansen test & - & - & - & - & - & - & 0.565 \\
Countries & 55 & 55 & 55 & 55 & 55 & 55 & 55 \\
Observations & 275 & 275 & 275 & 275 & 275 & 275 & 275 \\
\hline \hline
\end{tabular}

Note: Standard errors in parenthesis. ***,**, and * indicate significance at the 1,5, and 10 percent level, respectively. The standard errors in columns (1), (2), and (3) are clustered at the country level, while those from (4) to (6) are bootstrapped with 50 iterations. Column (7) uses collapsed instruments and an orthogonal transformation. All of the variables are in logarithms, while population growth and robots growth were transformed with the zero-skewness
$\log$ transformation. CorrFE refers to the corrected fixed effects with $b b$ indicating initialisation by the Blundell and Bond (1998) estimator, $a b$ initialisation by Arellano and Bond (1991) estimator, and $a h$ initialisation by the Anderson and Hsiao (1982) estimator. $\hat{p}_{t-1}$ is the growth rate of robot density (either manufacturing robots, or the total amount of robots per 1000 inhabitants) between periods $t-1$ and $t-2, n_{i, t-1}$ is the population growth rate between periods $t-1$ and $t-2$, and $s_{i, t-1}$ is the gross investment rate in period $t-1$. 
Table A.26: Total robots - sample with two extra years

\begin{tabular}{|c|c|c|c|c|c|c|c|}
\hline & $\begin{array}{c}(1) \\
\text { POLS }\end{array}$ & $\begin{array}{l}\text { (2) } \\
\mathrm{RE}\end{array}$ & $\begin{array}{l}\text { (3) } \\
\text { FE }\end{array}$ & $\begin{array}{c}(4) \\
\text { corrFE (bb) }\end{array}$ & $\begin{array}{c}(5) \\
\text { corrFE }(a b)\end{array}$ & $\begin{array}{c}\text { (6) } \\
\text { corrFE (ah) }\end{array}$ & $\begin{array}{c}\text { (7) } \\
\text { GMM (sys) }\end{array}$ \\
\hline$\hat{p}_{t-1}$ & & & & $\begin{array}{c}0.2452^{* * *} \\
(0.064)\end{array}$ & $\begin{array}{c}0.2207^{* * *} \\
(0.073)\end{array}$ & $\begin{array}{c}0.2395^{* * *} \\
(0.076)\end{array}$ & $\begin{array}{l}0.1326 \\
(0.094)\end{array}$ \\
\hline$n_{t-1}$ & $\begin{array}{l}-0.533^{*} \\
(0.281)\end{array}$ & $\begin{array}{c}-0.629^{* *} \\
(0.294)\end{array}$ & $\begin{array}{c}-1.101^{* *} \\
(0.440)\end{array}$ & $\begin{array}{l}-0.897^{*} \\
(0.459)\end{array}$ & $\begin{array}{c}-0.936^{* *} \\
(0.445)\end{array}$ & $\begin{array}{c}-0.908^{* *} \\
(0.456)\end{array}$ & $\begin{array}{c}-1.888^{* * *} \\
(0.570)\end{array}$ \\
\hline$s_{t-1}$ & $\begin{array}{c}0.073 \\
(0.120)\end{array}$ & $\begin{array}{c}0.093 \\
(0.127)\end{array}$ & $\begin{array}{c}0.268 \\
(0.400)\end{array}$ & $\begin{array}{c}0.191 \\
(0.299)\end{array}$ & $\begin{array}{c}0.210 \\
(0.281)\end{array}$ & $\begin{array}{c}0.213 \\
(0.289)\end{array}$ & $\begin{array}{c}-0.006 \\
(0.530)\end{array}$ \\
\hline Country FE & no & no & yes & yes & yes & yes & - \\
\hline Year Dummies & yes & yes & yes & yes & yes & yes & yes \\
\hline $\mathrm{AR}(2)$ test & - & - & - & - & - & - & 0.685 \\
\hline Hansen test & - & - & - & - & - & - & 0.138 \\
\hline Number of Countries & 60 & 60 & 60 & 60 & 60 & 60 & 60 \\
\hline Observations & 360 & 360 & 360 & 360 & 360 & 360 & 360 \\
\hline
\end{tabular}

Note: Standard errors in parenthesis. ***, **, and * indicate significance at the 1,5, and 10 percent level, respectively. The standard errors in columns (1), (2), and $(3)$ are clustered at the country level, while those from (4) to (6) are bootstrapped with 50 iterations. Column (7) uses collapsed instruments and an orthogonal transformation. All of the variables are in logarithms, while population growth and robots growth were transformed with the zero-skewness log transformation. CorrFE refers to the corrected fixed effects with $b b$ indicating initialisation by the Blundell and Bond (1998) estimator, $a b$ initialisation by Arellano and Bond (1991) estimator, and $a h$ initialisation by the Anderson and Hsiao (1982) estimator. $\hat{p}_{t-1}$ is the growth rate of robot density (either manufacturing robots, or the total amount of robots per 1000
inhabitants) between periods $t-1$ and $t-2, n_{i, t-1}$ is the population growth rate between periods $t-1$ and $t-2$, and $s_{i, t-1}$ is the gross investment rate in period $t-1$.

Table A.27: Manufacturing robots - sample with two extra years

\begin{tabular}{|c|c|c|c|c|c|c|c|}
\hline & $\begin{array}{c}(1) \\
\text { POLS }\end{array}$ & $\begin{array}{l}(2) \\
R E\end{array}$ & $\begin{array}{l}(3) \\
\text { FE }\end{array}$ & $\begin{array}{c}(4) \\
\text { corrFE (bb) }\end{array}$ & $\begin{array}{c}(5) \\
\text { corrFE (ab) }\end{array}$ & $\begin{array}{c}(6) \\
\text { corrFE (ah) }\end{array}$ & $\begin{array}{c}(7) \\
\text { GMM (sys) }\end{array}$ \\
\hline$\hat{p}_{t-1}$ & & & & $\begin{array}{c}0.2932^{* * *} \\
(0.060)\end{array}$ & $\begin{array}{c}0.2899^{* * *} \\
(0.059)\end{array}$ & $\begin{array}{c}0.2917^{* * *} \\
(0.061)\end{array}$ & $\begin{array}{l}0.1719 \\
(0.106)\end{array}$ \\
\hline$n_{t-1}$ & $\begin{array}{l}-0.520^{*} \\
(0.297)\end{array}$ & $\begin{array}{c}-0.638^{* *} \\
(0.306)\end{array}$ & $\begin{array}{c}-1.342^{* * *} \\
(0.452)\end{array}$ & $\begin{array}{c}-0.814^{*} \\
(0.460)\end{array}$ & $\begin{array}{c}-0.815^{*} \\
(0.456)\end{array}$ & $\begin{array}{c}-0.813^{*} \\
(0.461)\end{array}$ & $\begin{array}{c}-1.675^{* * *} \\
(0.628)\end{array}$ \\
\hline$s_{t-1}$ & $\begin{array}{c}0.038 \\
(0.088)\end{array}$ & $\begin{array}{c}0.048 \\
(0.093)\end{array}$ & $\begin{array}{c}0.097 \\
(0.411)\end{array}$ & $\begin{array}{l}-0.059 \\
(0.306)\end{array}$ & $\begin{array}{l}-0.040 \\
(0.297)\end{array}$ & $\begin{array}{l}-0.038 \\
(0.298)\end{array}$ & $\begin{array}{c}-0.303 \\
(0.431)\end{array}$ \\
\hline Country FE & no & no & yes & yes & yes & yes & - \\
\hline Year Dummies & yes & yes & yes & yes & yes & yes & yes \\
\hline $\mathrm{AR}(2)$ test & - & - & - & - & - & - & 0.750 \\
\hline Hansen test & - & - & - & - & - & - & 0.235 \\
\hline Number of Countries & 60 & 60 & 60 & 60 & 60 & 60 & 60 \\
\hline Observations & 360 & 360 & 360 & 360 & 360 & 360 & 360 \\
\hline
\end{tabular}

Note: Standard errors in parenthesis. ${ }^{* * *}, * *$, and ${ }^{*}$ indicate significance at the 1,5 , and 10 percent level, respectively. The standard errors in columns (1), (2), and $(3)$ are clustered at the country level, while those from (4) to (6) are bootstrapped with 50 iterations. Column (7) uses collapsed instruments and an orthogonal transformation. All of the variables are in logarithms, while population growth and robots growth were transformed with the zero-skewness log transformation. CorrFE refers to the corrected fixed effects with $b b$ indicating initialisation by the Blundell and Bond (1998) estimator, $a b$ initialisation by Arellano and Bond (1991) estimator, and $a h$ initialisation by the Anderson and Hsiao (1982) estimator. $\hat{p}_{t-1}$ is the growth rate of robot density (either manufacturing robots, or the total amount of robots per 1000
inhabitants) between periods $t-1$ and $t-2, n_{i, t-1}$ is the population growth rate between periods $t-1$ and $t-2$, and $s_{i, t-1}$ is the gross investment rate in period $t-1$.

Table A.28: Total robots - labour force growth

\begin{tabular}{|c|c|c|c|c|c|c|c|c|}
\hline & $\begin{array}{c}(1) \\
\text { POLS }\end{array}$ & $\begin{array}{l}\text { (2) } \\
\mathrm{RE}\end{array}$ & $\begin{array}{l}(3) \\
\text { RE }\end{array}$ & $\begin{array}{l}\text { (4) } \\
\text { OLS }\end{array}$ & $\begin{array}{c}5) \\
\text { OLS }\end{array}$ & $\begin{array}{l}\text { (6) } \\
\text { OLS }\end{array}$ & $\begin{array}{c}(7) \\
\text { OLS }\end{array}$ & $\begin{array}{l}\text { OLS } \\
\text { OLS }\end{array}$ \\
\hline$\hat{p}_{t-1}$ & & & & $\begin{array}{c}0.321^{* * *} \\
(0.072)\end{array}$ & $\begin{array}{c}0.262^{* * *} \\
(0.094)\end{array}$ & $\begin{array}{c}0.248^{* *} \\
(0.097)\end{array}$ & $\begin{array}{l}0.199^{* *} \\
(0.094)\end{array}$ & \\
\hline$n_{t-1}$ & $\begin{array}{l}-0.805^{*} \\
(0.403)\end{array}$ & $\begin{array}{c}-0.959^{* *} \\
(0.454)\end{array}$ & $\begin{array}{c}-1.541^{* *} \\
(0.635)\end{array}$ & $\begin{array}{c}-1.379^{* * *} \\
(0.465)\end{array}$ & $\begin{array}{c}-1.424^{* * *} \\
(0.447)\end{array}$ & $\begin{array}{c}-1.430^{* * *} \\
(0.449)\end{array}$ & $\begin{array}{c}-2.763^{* * * *} \\
(0.714)\end{array}$ & \\
\hline$s_{t-1}$ & $\begin{array}{c}0.062 \\
(0.103)\end{array}$ & $\begin{array}{c}0.090 \\
(0.113)\end{array}$ & $\begin{array}{c}0.493 \\
(0.451)\end{array}$ & $\begin{array}{c}0.385 \\
(0.353)\end{array}$ & $\begin{array}{c}0.393 \\
(0.330)\end{array}$ & $\begin{array}{c}0.402 \\
(0.331)\end{array}$ & $\begin{array}{l}-0.150 \\
(0.532)\end{array}$ & \\
\hline Country FE & no & no & yes & yes & yes & yes & - & \\
\hline Year Dummies & yes & yes & yes & yes & yes & yes & yes & \\
\hline $\mathrm{AR}(2)$ test & - & - & - & - & - & - & 0.387 & \\
\hline Hansen test & - & - & - & - & - & - & 0.123 & \\
\hline Number of Countries & 60 & 60 & 60 & 60 & 60 & 60 & 60 & \\
\hline Observations & 300 & 300 & 300 & 300 & 300 & 300 & 300 & \\
\hline
\end{tabular}

Note: Standard errors in parenthesis. ${ }^{* * *}, * *$, and ${ }^{*}$ indicate significance at the 1,5 , and 10 percent level, respectively. The standard errors in columns (1), $(2)$, and (3) are clustered at the country level, while those from (4) to (6) are bootstrapped with 50 iterations. Column (7) uses collapsed instruments and an orthogonal transformation. All of the variables are in logarithms, while labour force growth and robots growth were transformed with the zero-skewness log transformation. CorrFE refers to the corrected fixed effects with $b b$ indicating initialisation by the Blundell and Bond (1998) estimator, $a b$ initialisation by Arellano and Bond (1991) estimator, and $a /$ initilisation by the Anderson and Hsiao (1982) estimator. $p_{t-1}$ is the growth rate of robot density (either manufacturing robots, or the total amount of robots per 1000 inhabitants) between periods $t-1$ and $t-2, n_{i, t-1}$ is the labour force growth rate between periods $t-1$ and $t-2$, and $s_{i, t-1}$ is the gross
investment rate in period $t-1$. 
Table A.29: Manufacturing robots - labour force growth

\begin{tabular}{|c|c|c|c|c|c|c|c|c|}
\hline & $\begin{array}{c}(1) \\
\text { POLS }\end{array}$ & $\begin{array}{l}(2) \\
R E\end{array}$ & $\begin{array}{l}(3) \\
\text { RE }\end{array}$ & $\begin{array}{l}(4) \\
\text { OLS }\end{array}$ & $\begin{array}{c}5) \\
\text { OLS }\end{array}$ & $\begin{array}{c}(6) \\
\text { OLS }\end{array}$ & $\begin{array}{c}7) \\
\text { OLS }\end{array}$ & $\begin{array}{c}(8) \\
\text { OLS }\end{array}$ \\
\hline$\hat{p}_{t-1}$ & & & & $\begin{array}{c}0.372^{* * *} \\
(0.066)\end{array}$ & $\begin{array}{c}0.363^{* * *} \\
(0.069)\end{array}$ & $\begin{array}{c}0.3446^{* * *} \\
(0.074)\end{array}$ & $\begin{array}{l}0.194^{* *} \\
(0.097)\end{array}$ & \\
\hline$n_{t-1}$ & $\begin{array}{l}-0.811^{*} \\
(0.448)\end{array}$ & $\begin{array}{c}-0.971^{* *} \\
(0.491)\end{array}$ & $\begin{array}{c}-1.747^{* *} \\
(0.673)\end{array}$ & $\begin{array}{c}-1.506^{* * *} \\
(0.471)\end{array}$ & $\begin{array}{c}-1.518^{* * *} \\
(0.468)\end{array}$ & $\begin{array}{c}-1.531^{* * *} \\
(0.467)\end{array}$ & $\begin{array}{c}-2.924^{* * *} \\
(0.692)\end{array}$ & \\
\hline$s_{t-1}$ & $\begin{array}{c}0.037 \\
(0.080)\end{array}$ & $\begin{array}{c}0.051 \\
(0.084)\end{array}$ & $\begin{array}{c}0.272 \\
(0.469)\end{array}$ & $\begin{array}{c}0.103 \\
(0.352)\end{array}$ & $\begin{array}{c}0.103 \\
(0.344)\end{array}$ & $\begin{array}{c}0.112 \\
(0.343)\end{array}$ & $\begin{array}{l}-0.087 \\
(0.268)\end{array}$ & \\
\hline Country FE & no & no & yes & yes & yes & yes & - & \\
\hline Year Dummies & yes & yes & yes & yes & yes & yes & yes & \\
\hline $\mathrm{AR}(2)$ test & - & - & - & - & - & - & 0.713 & \\
\hline Hansen test & - & - & - & - & - & - & 0.411 & \\
\hline Number of Countries & 60 & 60 & 60 & 60 & 60 & 60 & 60 & \\
\hline Observations & 300 & 300 & 300 & 300 & 300 & 300 & 300 & \\
\hline
\end{tabular}

Note: Standard errors in parenthesis. ${ }^{* * *}$, **, and ${ }^{*}$ indicate significance at the 1,5 , and 10 percent level, respectively. The standard errors in columns (1), (2), and (3) are clustered at the country level, while those from (4) to (6) are bootstrapped with 50 iterations. Column (7) uses collapsed instruments and an orthogonal transformation. All of the variables are in logarithms, while labour force growth and robots growth were transformed with the zero-skewness log transformation. CorrFE refers to the corrected fixed effects with $b b$ indicating initialisation by the Blundell and Bond (1998) estimator, $a b$ initialisation by Arellano and Bond (1991) estimator, and $a h$ initialisation by the Anderson and Hsiao (1982) estimator. $\hat{p}_{t-1}$ is the growth rate of robot density (either manufacturing robots, or the total amount of robots per 1000 inhabitants) between periods $t-1$ and $t-2, n_{i, t-1}$ is the labour force growth rate between periods $t-1$ and $t-2$, and $s_{i, t}-1$ is the gross investment rate in period $t-$ 
A concern could arise that our results are dependent on the zero-skewness log transformation. A further robustness check therefore relies on using the neglog transformation for both the population growth rate and the robot density growth rate. The neglog transformation involves the following adjustments to a variable (which we call $x$ for simplicity): If $x<=0$, then we use $-\ln (-x+1)$ instead of $x$; if $x>0$, then we use $\ln (x+1)$ instead of $x$. The results are shown in Tables A.30 and A.31. Again, the results remain similar to the baseline specification in terms of the sign and the statistical significance, although the size of the coefficients is much larger.

Table A.30: Total robots - neglog transformation

\begin{tabular}{|c|c|c|c|c|c|c|c|}
\hline & $\begin{array}{c}(1) \\
\text { POLS }\end{array}$ & $\begin{array}{l}(2) \\
\text { RE }\end{array}$ & $\begin{array}{l}\text { (3) } \\
\text { FE }\end{array}$ & $\begin{array}{c}(4) \\
\text { corrFE (bb) }\end{array}$ & $\begin{array}{c}(5) \\
\text { corrFE }(a b)\end{array}$ & $\begin{array}{c}(6) \\
\text { corrFE (ah) }\end{array}$ & $\begin{array}{c}(7) \\
\text { GMM (sys) }\end{array}$ \\
\hline$\hat{p}_{t-1}$ & & & & $\begin{array}{c}0.496^{* * *} \\
(0.068)\end{array}$ & $\begin{array}{c}0.477^{* * *} \\
(0.081)\end{array}$ & $\begin{array}{c}0.456^{* * *} \\
(0.092)\end{array}$ & $\begin{array}{c}0.473^{* * *} \\
(0.105)\end{array}$ \\
\hline$n_{t-1}$ & $\begin{array}{c}-12.135^{*} \\
(6.436)\end{array}$ & $\begin{array}{c}-15.798^{* *} \\
(6.399)\end{array}$ & $\begin{array}{l}-35.286^{*} \\
(18.480)\end{array}$ & $\begin{array}{c}-20.726^{* *} \\
(10.299)\end{array}$ & $\begin{array}{c}-21.720^{* *} \\
(10.138)\end{array}$ & $\begin{array}{c}-22.657^{* *} \\
(9.892)\end{array}$ & $\begin{array}{c}-40.401^{* * *} \\
(14.349)\end{array}$ \\
\hline$s_{t-1}$ & $\begin{array}{c}0.321 \\
(0.430)\end{array}$ & $\begin{array}{c}0.499 \\
(0.475)\end{array}$ & $\begin{array}{l}2.409^{* *} \\
(0.957)\end{array}$ & $\begin{array}{c}1.275 \\
(0.909)\end{array}$ & $\begin{array}{c}1.327 \\
(0.916)\end{array}$ & $\begin{array}{c}1.383 \\
(0.921)\end{array}$ & $\begin{array}{l}-0.575 \\
(1.030)\end{array}$ \\
\hline Country FE & no & no & yes & yes & yes & yes & - \\
\hline Year FE & yes & yes & yes & yes & yes & yes & yes \\
\hline $\mathrm{AR}(2)$ test & - & - & - & - & - & - & 0.100 \\
\hline Hansen test & - & - & - & - & - & - & 0.186 \\
\hline Countries & 60 & 60 & 60 & 60 & 60 & 60 & 60 \\
\hline Observations & 300 & 300 & 300 & 300 & 300 & 300 & 300 \\
\hline
\end{tabular}

Note: Standard errors in parenthesis. ******, and * indicate significance at the 1,5 , and 10 percent level, respectively. The standard errors in columns (1), $(2)$, and (3) are clustered at the country level, while those from (4) to (6) are bootstrapped with 50 iterations. Column (7) uses collapsed instruments and an orthogonal transformation. All of the variables are in logarithms, while population growth and robots growth were transformed with the zero-skewness log transformation CorrFE refers to the corrected fixed effects with $b b$ indicating initialisation by the Blundell and Bond (1998) estimator, $a b$ initialisation by Arellano and Bond (1991) estions a anount gross investment rate in period $t-1$.

Table A.31: Manufacturing robots - neglog transformation

\begin{tabular}{lccccccc}
\hline \hline & $(1)$ & $(2)$ & $(3)$ & $(4)$ & $(5)$ & $(6)$ & $(7)$ \\
& POLS & RE & FE & corrFE (bb) & corrFE (ab) & corrFE (ah) & GMM (sys) \\
\hline \multirow{2}{*}{$\hat{p}_{t-1}$} & & & & & & & \\
& & & & $0.257^{* * *}$ & $0.192^{* *}$ & $0.174^{*}$ & $0.186^{*}$ \\
$n_{t-1}$ & -4.084 & $-5.570^{*}$ & $-16.691^{* *}$ & $-14.854^{* * *}$ & $-15.714^{* * *}$ & $-15.892^{* * *}$ & $-23.165^{* * *}$ \\
& $(2.791)$ & $(3.069)$ & $(7.375)$ & $(4.150)$ & $(3.880)$ & $(3.846)$ & $(8.161)$ \\
$s_{t-1}$ & 0.030 & 0.049 & 0.266 & 0.219 & 0.237 & 0.247 & 0.152 \\
& $(0.094)$ & $(0.100)$ & $(0.469)$ & $(0.369)$ & $(0.347)$ & $(0.347)$ & $(0.355)$ \\
& & & & & & & \\
\hline Country FE & no & no & yes & yes & yes & yes & - \\
Year FE & yes & yes & yes & yes & yes & yes & yes \\
AR(2) test & - & - & - & - & - & - & 0.798 \\
Hansen test & - & - & - & - & - & - & 0.219 \\
Countries & 60 & 60 & 60 & 60 & 60 & 60 & 60 \\
Observations & 300 & 300 & 300 & 300 & 300 & 300 & 300 \\
\hline \hline
\end{tabular}

Note: Standard errors in parenthesis. ***,**, and * indicate significance at the 1,5, and 10 percent level, respectively. The standard errors in columns (1), (2), and (3) are clustered at the country level, while those from (4) to (6) are bootstrapped with 50 iterations. Column (7) uses collapsed instruments and an orthogonal transtormation. All of the variables are in logarithms, while population growth and robots growth were transformed with the zero-skewnes
$\log$ transformation. CorrFE refers to the corrected fixed effects with $b b$ indicating initialisation by the Blundell and Bond (1998) estimator, $a b$ initialisation by Arellano and Bond (1991) estimator, and ah initialisation by the Anderson and Hsiao (1982) estimator. $\hat{p}_{t-1}$ is the growth rate of robot density (either manufacturing robots, or the total amount of robots per 1000 inhabitants) between periods $t-1$ and $t-2, n_{i, t}-1$ is the population growth rate between periods $t-1$ and $t-2$, and $s_{i, t-1}$ is the gross investment rate in period $t-1$. 
Our final robustness check follows Graetz and Michaels (2018) and converts the dependent variable into percentiles. Consequently, we include the population growth rate without the logarithmic transformation as regressor. We estimate, as before, a pooled OLS and a random effects specification. We also add continent dummies to the latter to further control for differences related to the geographical location. Finally, we also include several crosssectional regressions for different time periods. Tables A.32 and A.33 show the results. Naturally, the coefficient estimates can no longer be interpreted as elasticities. We observe that the qualitative relationships between the variables remains the same as in our baseline regressions and that the coefficients are statistically significant in most of the specifications (the investment rate is sometimes also significant, as seen in Table A.32). Given the nature of our dependent variable, we refrain from using the fixed effects estimator. In this scenario the preferred specification is the one obtained with the random effects estimator. Both tables show that a one percent increase in the population growth rate is associated with a decrease of approximately two percentiles in the growth of the robot density. Adding the continent dummies does not contribute much additional explanatory power, and the magnitude of the coefficient of interest barely changes. With regards to the cross-sections, we rank the robot density growth rates to avoid splitting them into percentiles with only 60 observations. The coefficient of interest is still significant in most specifications and has the predicted negative sign. However, in columns (5) and (7) from both tables, the coefficient loses statistical significance. Since columns (5) and (7) correspond to periods that include 2001 and 2008, respectively, this could be due to the dot-com crisis and the global financial crisis.

Table A.32: Total robots - percentiles as the dependent variable

\begin{tabular}{lcccccccc}
\hline \hline & $(1)$ & $(2)$ & $(3)$ & $(4)$ & $(5)$ & $(6)$ & $(7)$ & $(8)$ \\
& POLS & RE & RE & OLS & OLS & OLS & OLS & OLS \\
\hline \multirow{4}{*}{$n_{t-1}$} & $-1.862^{* * *}$ & $-2.053^{* * *}$ & $-2.144^{* *}$ & $-3.323^{* * *}$ & -0.142 & $-1.027^{* *}$ & -0.870 & $-1.671^{* * *}$ \\
& $(0.653)$ & $(0.651)$ & $(0.996)$ & $(0.387)$ & $(0.355)$ & $(0.369)$ & $(1.061)$ & $(0.316)$ \\
$s_{t-1}$ & 0.649 & $0.721^{*}$ & $0.765^{*}$ & 0.741 & 0.392 & $0.687^{*}$ & 0.213 & 0.434 \\
& $(0.415)$ & $(0.395)$ & $(0.404)$ & $(0.422)$ & $(0.301)$ & $(0.323)$ & $(0.290)$ & $(0.365)$ \\
& & & & & & & & \\
\hline Period & All & All & All & $1999-2001$ & $2002-2004$ & $2005-2007$ & $2008-2010$ & $2011-2013$ \\
FE & Year & Year & Year + Continent & - & - & - & - & - \\
Observations & 300 & 300 & 300 & 60 & 60 & 60 & 60 & 60 \\
\hline \hline
\end{tabular}

Note: Standard errors in parenthesis. ${ }^{* * *}$, **, and ${ }^{*}$ indicate significance at the 1,5 , and 10 percent level, respectively. The standard errors in columns (1), (2), and (3) are clustered at the country level, while those from (4) to (6) are clustered at the continent level. The dependent variable of columns (1) to (3) is the percentile of the distribution of the robot density growth, while the one of columns (3) to (6) is the country rank. $\hat{p}_{t-1}$ is the growth rate of robot density (either manufacturing robots, or the total amount of robots per 1000 growth growth rate of robot density (either manufacturing robots, or the total amount of robots per 1000 inhabitants) between periods $t-1$ and $t-2, n_{i, t}-1$ is the population growth rate
between periods $t-1$ and $t-2$, and $s_{i, t-1}$ is the gross investment rate in period $t-1$.

Table A.33: Manufacturing robots - percentiles as the dependent variable

\begin{tabular}{|c|c|c|c|c|c|c|c|c|}
\hline & (1) & (2) & (3) & (4) & (5) & (6) & (7) & (8) \\
\hline$n_{t-1}$ & $\begin{array}{c}-1.689^{* *} \\
(0.748)\end{array}$ & $\begin{array}{c}-1.863^{* *} \\
(0.729)\end{array}$ & $\begin{array}{l}-2.080^{*} \\
(1.064)\end{array}$ & $\begin{array}{c}-3.011^{* * *} \\
(0.537)\end{array}$ & $\begin{array}{c}0.183 \\
(0.360)\end{array}$ & $\begin{array}{c}-0.820^{* *} \\
(0.287)\end{array}$ & $\begin{array}{l}-0.880 \\
(0.758)\end{array}$ & $\begin{array}{c}-1.537^{* * *} \\
(0.292)\end{array}$ \\
\hline$s_{t-1}$ & $\begin{array}{c}0.594 \\
(0.415)\end{array}$ & $\begin{array}{c}0.612 \\
(0.393)\end{array}$ & $\begin{array}{c}0.647 \\
(0.403)\end{array}$ & $\begin{array}{c}0.670 \\
(0.338)\end{array}$ & $\begin{array}{c}0.345 \\
(0.284)\end{array}$ & $\begin{array}{l}0.817^{* *} \\
(0.305)\end{array}$ & $\begin{array}{c}0.004 \\
(0.347)\end{array}$ & $\begin{array}{c}0.427 \\
(0.360)\end{array}$ \\
\hline Period & All & All & All & 1999-2001 & $2002-2004$ & $2005-2007$ & $2008-2010$ & $2011-2013$ \\
\hline FE & Year & Year & Year + Continent & - & - & - & - & - \\
\hline Observations & 300 & 300 & 300 & 60 & 60 & 60 & 60 & 60 \\
\hline
\end{tabular}




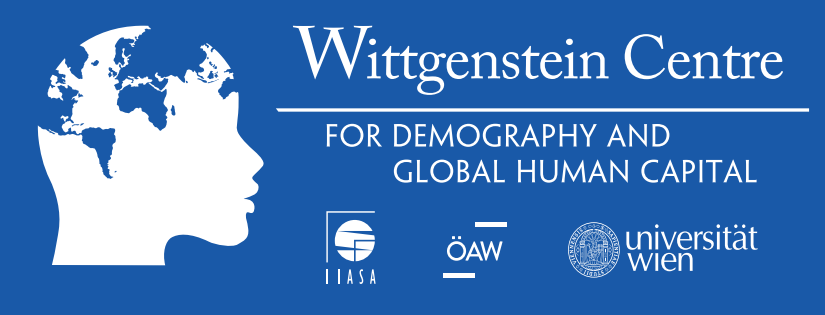

The Wittgenstein Centre is a collaboration among the Austrian Academy of Sciences (ÖAW), the International Institute for Applied Systems Analysis (IIASA) and the University of Vienna. 